Bài báo khoa học

\title{
Thử nghiệm đồng hóa số liệu gió vệ tinh và số liệu cao không để mô phỏng qũy đạo và cường độ cơn bão Haiyan 2013
}

\author{
Trần Thị Mai Hương ${ }^{1, *}$, Nguyễn Thị Hằng², Nguyễn Văn Tín ${ }^{3}$, Trần Văn Sơnn ${ }^{1}$, Phạm \\ Thị Minh ${ }^{1}$ \\ ${ }^{1}$ Khoa Khí tượng Thủy văn và Biến đổi khí hậu, Trường Đại học Tài nguyên và Môi trường \\ TP.HCM; ttmhuong@hcmunre.edu.vn; tvson@hcmunre.edu.vn; \\ minhpt201@gmail.com. \\ 2 Khoa Đại cương, Trường Đại học Tài nguyên và Môi trường TP. HCM; \\ hang.nguyen687@gmail.com \\ 3 Khoa Quản lý Tài nguyên Biển và hải đảo, Trường Đại học Tài nguyên và Môi trường TP. \\ HCM; nvtin@hcmunre.edu.vn \\ * Tác giả liên hệ: ttmhuong@hcmunre.edu.vn; Tel.: +84-932676905
}

Ban Biên tập nhận bài: 12/6/2020; Ngày phản biện xong: 18/8/2020; Ngày đăng bài: $25 / 8 / 2020$

Tóm tắt: Nghiên cứu tiến hành các thử nghiệm với việc đồng hóa số liệu gió vệ tinh (CIMSS), số liệu cao không (RADS) và số liệu hỗn hợp (gió vệ tinh và số liệu cao không MIX) bằng phương pháp lọc Kalman tổ hợp. Kết quả thử nghiệm cho thấy, ứng với mỗi loại số liệu quan trắc, các mô phỏng đường dòng (hoàn lưu khí quyển mô phỏng) trong các thử nghiệm là khác nhau. Trong đó thử nghiệm CIMSS, RADS và MIX mô phỏng xu thế cũng như cường độ của hoàn lưu chung khí quyển giống với sự phát triển thực tế hơn so với thử nghiệm không sử dụng số liệu quan trắc $(\mathrm{MPH})$, nhờ đó quỹ đạo bão Haiyan được mô phỏng khá phù hợp với quỹ đạo thực, sai số thống kê trong 4 trường hợp thử nghiệm giảm đáng kể. Cụ thể, sai số quỹ đạo trong thử nghiệm CIMSS cải thiện $14,0 \%$ và $14,3 \%$ so với thử nghiệm $\mathrm{MPH}$, và giảm lần lượt $14,0 \%$ và $23,9 \%$ so với kết quả dự báo toàn cầu GFS ở hạn dự báo 48 giờ và 72 giờ, trong thử nghiệm RADS sai số qũy đạo cải thiện $11,1 \%$ so với GFS và $\mathrm{MPH}$ ở hạn 60 giờ, và sai số quỹ đạo trong thử nghiệm MIX giảm 12\% và $14,2 \%$ so với GFS ở hạn 60 giờ và 72 giờ, ngoài ra thử nghiệm MIX có sai số qũy đạo giảm $12 \%$ so với thử nghiệm $\mathrm{MPH}$ ở hạn 60 giờ. Về cường độ bão, dự báo Pmin trong các thử nghiệm MPH, CIMSS, RADS và MIX tốt hơn so với số liệu GFS. Trong đó sai số Pmin trong thử nghiệm CIMSS nhỏ hơn sai số Pmin trong các thử nghiệm còn lại và số liệu GFS ở hạn dự báo dài hơn 48 giờ. Đối với Vmax, các thử nghiệm CIMSS, RADS và MIX dự báo Vmax hiệu quả ở hạn dự báo 60 và 72 giờ.

Từ khóa: Lọc Kalman; Mô hình WRF; Bão; Dự báo tổ hợp.

\section{Mở đầu}

Số liệu gió vệ tinh và số liệu cao không đều là đầu vào chính cho hệ thống đồng hóa số liệu toàn cầu NCEP (GDAS: Global Data Assimilation System) để tạo ra phân tích cuối cùng tầng đối lưu, nhưng số liệu phân tích trên được đưa vào mô hình dự báo toàn cầu và tạo ra các sản phẩm dự báo toàn cầu có độ phân giải thô $(0,5$ độ) và thường dự báo thấp hơn so với quan trắc. Vì vậy khi sử dụng sản phẩm của mô hình dự báo toàn cầu làm đầu vào cho mô hình khu 
vực, quá trình nội suy trong mô hình khu vực đã làm mất đi các thông tin mô phỏng hoàn lưu qui mô lớn dẫn đến kết quả dự báo không chính xác, đặc biệt với dự báo bão.

Mặt khác các nghiên cứu gần đây về lọc Kalman tổ hợp đã chứng minh khả năng đồng hóa nhiều loại quan trắc ở các qui mô khác nhau của sơ đồ đồng hóa Kalman tổ hợp [1-5]. Nghiên cứu trước đây [5] cho thấy số liệu vệ tinh đồng hóa bằng lọc Kalman ứng dụng trong mô hình WRF cải thiện đáng kể kết quả dự báo quỹ đạo cơn bão Megi 2010, và đưa ra nhận định về vai trò của các quan trắc ngoài rìa xa tâm bão có thể đóng góp đáng kể trong việc nâng cao kỹ năng dự báo quỹ đạo và cường độ bão.

Ngoài ra, bão là hiện tượng thời tiết có tính bất định cao, nên việc dự báo quỹ đạo và cường độ bão vẫn còn là thách thức đối với các nhà khí tượng trên thế giới. Do vậy trong nghiên cứu này chúng tôi khảo sát tác động của số liệu quan trắc lên mô phỏng quỹ đạo và cường độ bão Haiyan 2013 thông qua lọc Kalman tổ hợp đồng hóa các số liệu nói trên trong mô hình.

\section{Phương pháp nghiên cứu}

\subsection{Hoạt động của con bão Haiyan}

Bão Hải Yến (tên quốc tế Haiyan, số hiệu quốc tế 1330, số hiệu Việt Nam là bão số 13). Bão số 13 là cơn bão rất mạnh về cường độ có thể so sánh với bão Katrina đổ bộ vào nước Mỹ năm 2005 , hình thành ở vĩ độ thấp $\left(6,1^{\circ} \mathrm{N}\right)$ (hình 1 ), đổ bộ vào Philipines với cường độ trên cấp 17 , sau đó đi vào Biển Đông vẫn giữ cường độ cấp 14 , cấp 15 , đổi hướng di chuyển lên phía bắc đổ bộ vào Hải Phòng-Quảng Ninh với cường độ gió cấp 11 , cấp 12 và giật đến cấp. Bão gây ra gió giật mạnh cấp 6-7 ở vùng ven biển các tỉnh Bắc và Trung Trung Bộ, ở vùng đồng bằng và trung du Bắc Bộ có gió mạnh cấp $6-7$, có nơi cấp 8 , giật cấp $9-10$, ở vùng duyên hải Bắc Bộ và khu Đông Bắc Bắc Bộ có gió mạnh cấp 8-11, giật cấp 12-13 [6].

Trị số khí áp thấp nhất trong thời gian hoạt động của bão Haiyan quan trắc được tại trạm khí tượng Bãi Cháy (Quảng Ninh) là $981.2 \mathrm{hPa}$ (lúc 3 giờ 30 phút ngày 11/11/2013). Do ảnh hưởng của bão, ở các tỉnh phía đông bắc bộ, ven Biển Bắc và Trung Trung Bộ có mưa vừa, mưa to, riêng khu Đông Bắc Bộ có mưa to đến rất to. Tổng lượng mưa từ 13 giờ ngày 9 tháng 11 đến 19 giờ ngày 11 tháng 11 , phổ biến 50-100 mm, riêng tỉnh Quảng Ninh 100-150 mm, một số nơi lớn hơn như Bãi Cháy $183 \mathrm{~mm}$....Khi bão Haiyan đổ bộ vào Quảng Ninh-Hải Phòng gây hậu quả rất lớn về người và tài sản. Đã có 18 người chết, 2 người mất tích, 93 người bị thương, 149 ngôi nhà bị đổ, sập, trôi, hư hại; 4.567 ngôi nhà bị ngập, 2.918 ngôi nhà bị tốc mái, 3.828 ha lúa bị ngập úng, đồ; 52.368 ha ngô, sắn, hoa màu bị ngập, 8.132 gia súc gia cầm bị chết cuốn trôi, 23 công trình thủy lợi bị hư hại. Ước tính tổng thiệt hại 669,530 tỷ đồng [6].

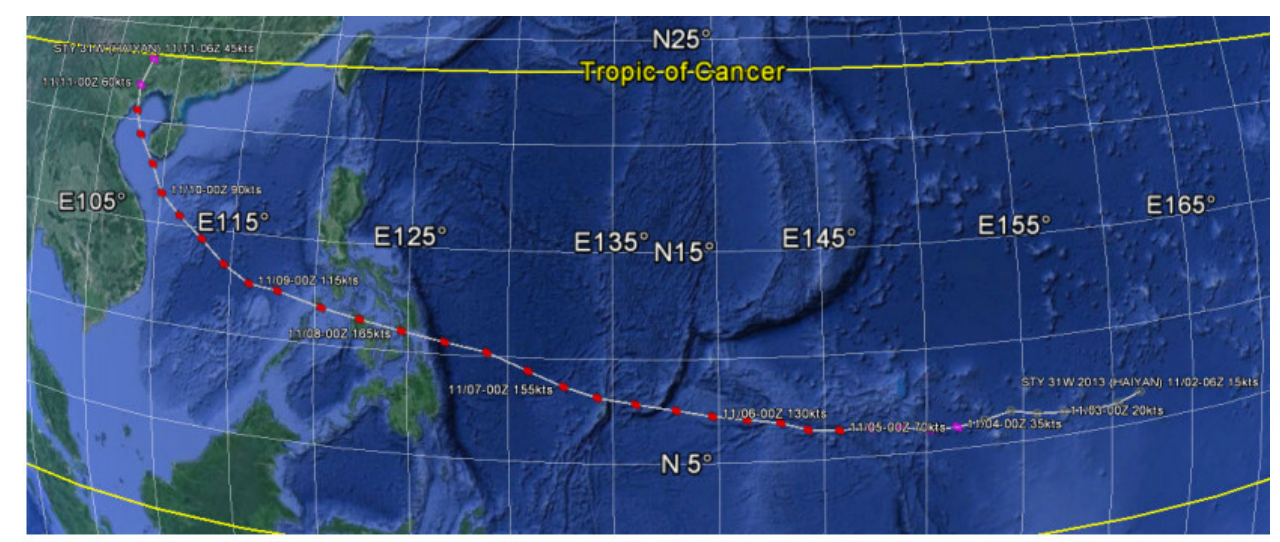

Hình 1. Diễn biến đường đi của cơn bão Haiyan 2013 [7]. 


\subsection{Thiết kế thí nghiệm}

\subsubsection{Mô hình}

Sử dụng mô hình WRF phiên bản V3.3.1 với 31 mực (sigma) theo phương thẳng đứng với mực khí áp cao nhất (biên trên của mô hình) có giá trị là $10 \mathrm{hPa}$ [8]. Mô hình WRF được lựa chọn với hai miền tính lồng ghép sử dụng phép chiếu Mercator. Miền lưới thiết kế cho thử nghiệm mô phỏng cơn bão Haiyan là lưới lồng gồm 2 miền tính với độ phân giải ngang tương ứng $36 \mathrm{~km}$ và $12 \mathrm{~km}$, miền lưới 1 gồm $171 \times 141$ điểm lưới và miền lưới 2 gồm $232 \times 160$ điểm lưới với tâm miền tính cố định $17^{\circ} \mathrm{N}$ và $118,2^{\circ} \mathrm{E}$ (hình 2 ) sử dụng trong mô hình WRF.

Để khảo sát tác động của số liệu quan trắc trong mô phỏng quỹ đạo và cường độ bão Haiyan 2013, nghiên cứu tiến hành thử nghiệm dự báo cơn bão Haiyan 2013 với hạn 3 ngày với thời điểm bắt đầu dự báo từ $00 \mathrm{Z} 07$ đến $12 \mathrm{Z08}$, theo các trường hợp: a) dự báo tổ hợp với các tổ hợp vật lý khác nhau $(\mathrm{MPH})$; b) Dự báo với điều kiện ban đầu được tạo ra từ lọc Kalman tổ hợp đồng hóa số liệu vệ tinh (CIMSS); c) Dự báo với điều kiện ban đầu được tạo ra từ lọc Kalman tổ hợp đồng hóa số liệu cao không (RADS); d) Dự báo với điều kiện ban đầu được tạo ra từ lọc Kalman tổ hợp đồng hóa số liệu hỗn hợp vệ tinh và cao không (MIX) với 21 thành phần tổ hợp.

Các thí nghiệm trong nghiên cứu đều tiến hành thử nghiệm cho 21 thành phần tổ hợp sơ đồ vật lý khác nhau tương ứng với 21 lần dự báo. Hiện tại trong mô hình WRF V3.3.1 có các sơ đồ tham số hóa vi vật lý, tham số hóa bức xạ sóng dài và sóng ngắn, tham số hóa đối lưu; tương ứng với các lựa chọn như trong bảng 1 , do đó có thể kết hợp giữa các sơ đồ vật lý khác nhau đó để tạo ra thành phần tổ hợp tương ứng với 1 dự báo (Bảng 2).

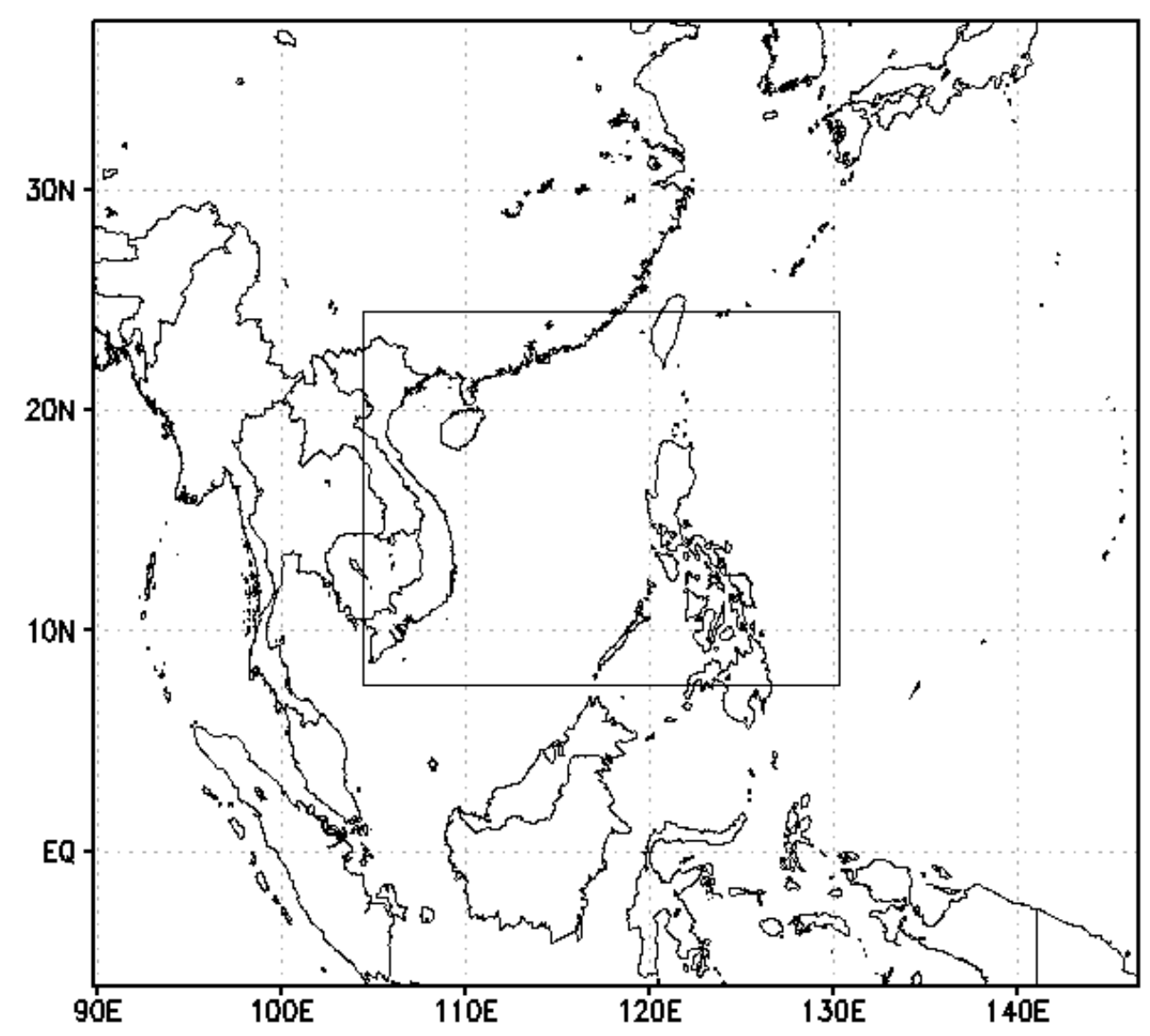

Hình 2. Miền lưới thử nghiệm. 
Bảng 1. Sơ đồ tham số hóa trong mô hình WRF ứng với các lựa chọn cụ thể.

\begin{tabular}{|c|c|c|}
\hline Sơ đồ & Kí hiệu & Các lựa chọn \\
\hline \multirow{6}{*}{ Vi vật lý } & \multirow{6}{*}{ mp_physics } & $=1$, Kessler scheme \\
\hline & & $=2$, Lin et al. scheme \\
\hline & & $=3$, WSM 3-class simple ice scheme \\
\hline & & $=4$, WSM 5-class scheme \\
\hline & & $=5$, Ferrier (new Eta) microphysics \\
\hline & & $=6$, WSM 6-class graupel scheme \\
\hline \multirow{2}{*}{ Bức xạ sóng ngắn } & \multirow{2}{*}{ ra_sw_physics } & $=1$, Dudhia scheme \\
\hline & & $=2$, Goddard short wave \\
\hline Bức xạ sóng dài & ra_lw_physics & $=1$, rrtm scheme \\
\hline Đối lưu & cu_physics & $\begin{array}{l}=1, \text { Kain-Fritsch (new Eta) scheme } \\
=2, \text { Betts-Miller-Janjic scheme }\end{array}$ \\
\hline
\end{tabular}

Bảng 2. Thành phần tổ hợp tương ứng với các sơ đồ vật lý khác nhau.

\begin{tabular}{|c|c|c|c|c|}
\hline Tổ hợp & Ra_lw_physics & Ra_sw_physics & mp_physics & cu_physics \\
\hline 001 & 1 & 2 & 1 & 1 \\
\hline 002 & 1 & 1 & 1 & 2 \\
\hline 003 & 1 & 2 & 1 & 2 \\
\hline 004 & 1 & 1 & 2 & 1 \\
\hline 005 & 1 & 2 & 2 & 1 \\
\hline 006 & 1 & 1 & 2 & 2 \\
\hline 007 & 1 & 2 & 2 & 2 \\
\hline 008 & 1 & 1 & 3 & 1 \\
\hline 009 & 1 & 2 & 3 & 1 \\
\hline 010 & 1 & 1 & 3 & 2 \\
\hline 011 & 1 & 2 & 3 & 2 \\
\hline 012 & 1 & 1 & 4 & 1 \\
\hline 013 & 1 & 2 & 4 & 1 \\
\hline 014 & 1 & 1 & 4 & 2 \\
\hline 015 & 1 & 2 & 4 & 2 \\
\hline 016 & 1 & 1 & 5 & 1 \\
\hline 017 & 1 & 2 & 5 & 1 \\
\hline 018 & 1 & 1 & 5 & 2 \\
\hline 019 & 1 & 2 & 5 & 2 \\
\hline 020 & 1 & 1 & 6 & 1 \\
\hline 021 & 1 & 2 & 6 & 1 \\
\hline
\end{tabular}

\subsubsection{Số liệu}

Điều kiện đầu vào và điều kiện biên sử dụng số liệu dự báo GFS của NCEP/NCAR (NCEP-The National Center for Environmental Prediction/NCAR-The National Center for Atmospheric Research) có độ phân giải ngang là $0,5 \times 0,5$ độ kinh vĩ và định dạng grib2. Số liệu GFS được lấy từ trang web: https://www.ncdc.noaa.gov/data-access/model-data/model-datasets/global-forcast-system - gfs. 
Số liệu quan trắc gió từ vệ tinh là một nguồn số liệu đặc biệt quan trọng đối với các mô hình dự báo chạy nghiệp vụ trên thế giới với độ phủ sóng toàn cầu và thời gian thu thập số liệu trong vòng từ 3-6 giờ phụ thuộc vào đặc tính của từng vệ tinh. Số liệu gió vệ tinh cho phép biết được tình trạng động lực của khí quyển góp phần bồ sung thông tin cho trường ban đầu của mô hình dự báo bằng đồng hóa số liệu. Hiện nay tổ chức hợp tác nghiên cứu vệ tinh khí tượng Trường Đại học Wisconsin (Cooperative Institute for Meteorological Satellite Studies-University of Wisconsin satellite atmospheric motion vector CIMSS-AMV) xử lý và cung cấp gió vệ tinh. Một số các nghiên cứu với số liệu CIMSS-AMV đã chỉ ra số liệu này có thể giúp cải thiện chất lượng dự báo của các hệ thống quy mô trung bình khác nhau [5, 10]. Uuu điểm của số liệu CIMSS-AMV là số liệu đã được kiểm định với chất lượng cao và được xác định bằng thuật toán lọc đệ quy. Mỗi một số liệu được kiểm tra sao cho phù hợp hầu hết với số liệu xung quanh bằng kĩ thuật chỉ số chất lượng. Hầu hết số liệu CIMSS-AMV phân bố trong các vùng khác nhau và hiện tại được lưu trữ trong nhiều định dạng bao gồm ASCII và/hoặc BUFR. Trong nghiên cứu này số liệu gió vệ tinh được lấy ở khu vực Ần Độ, Tây Bắc Thái Bình Dương (hình 3 ) và được downloads từ trang website http://tropic.ssec.wisc.edu trong định dạng ASCII.

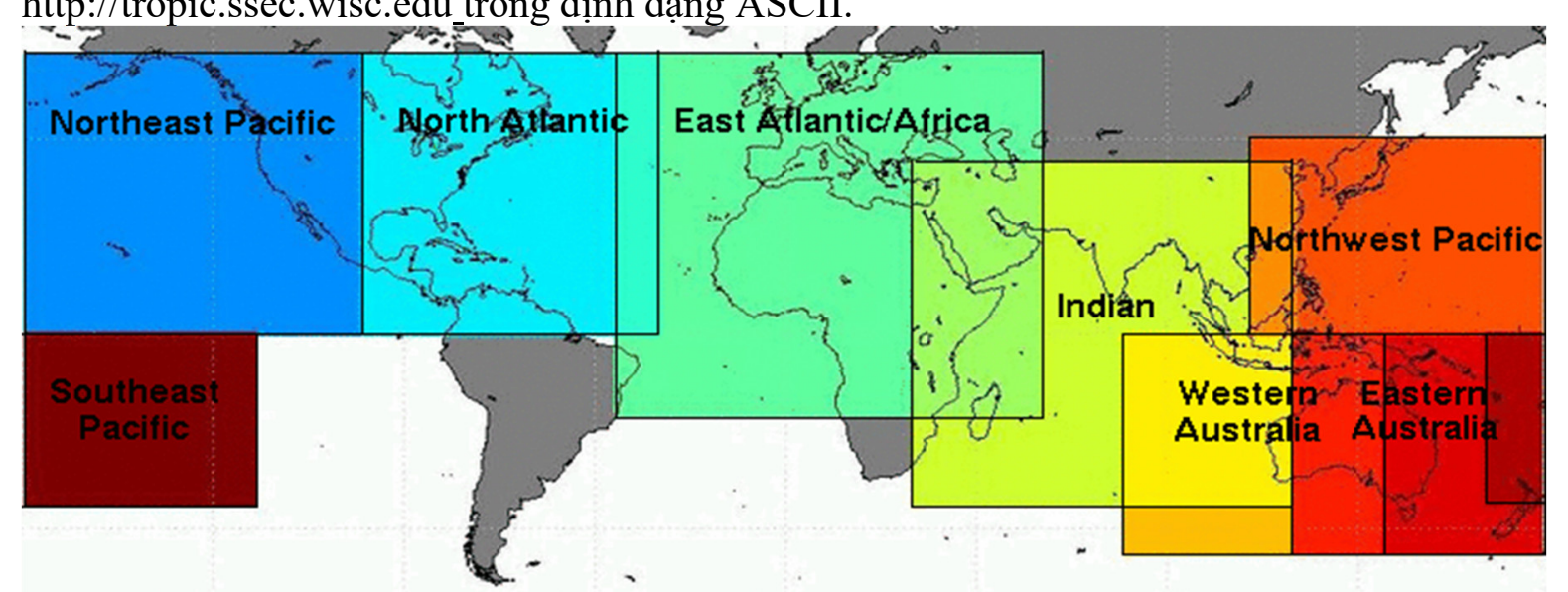

Hình 3. Khu vực có số liệu gió quan trắc từ vệ tinh [9].

Số liệu quan trắc cao không là một trong những nguồn số liệu quan trắc có giá trị và thống nhất trong khí tượng học. Quan trắc trên cao được bắt đầu từ những năm 1940. Hiện nay, khoảng 1000 trạm đã được tổ chức ở 90 nước trên thế giới thực hiện quan trắc lên tới 4 lần trong một ngày tại các thời gian quy định quốc tế. Ở Châu Á, số lượng các trạm quan trắc cao không được bổ sung ngày một nhiều hơn. Các yếu tố quan trắc trên cao bao gồm áp suất, độ cao địa thế vị, nhiệt độ không khí, nhiệt độ điểm sương, tốc độ và hướng gió. Số liệu cao không được lấy từ trang $\mathrm{http}: / /$ weather.uwyo.edu/upperair/sounding.html. Số liệu này được đưa vào chương trình kiểm tra chất lượng số liệu quan trắc trong module WRFDA trước khi đồng hóa, nhằm loại bỏ các số liệu cao không không phù hợp với tiêu chuẩn sai số dựa vào sai số thống kê do NCEP cung cấp. Số liệu quan trắc cao không được lưu trữ dưới dạng ASCII (số trạm cao không được sử dụng trong nghiên cứu được thể hiện trong bảng 3 và hình 4$)$.

Bảng 3. Số trạm cao không được đưa vào đồng hóa trong 4 trường hợp thử nghiệm.

\begin{tabular}{cccc}
\hline STT & Thời điểm dự báo & Số trạm ban đầu & Số trạm đưa vào đồng hóa \\
\hline 1 & $00 \mathrm{~h}-07 / 11 / 2013$ & 89 & 56 \\
2 & $12 \mathrm{~h}-07 / 11 / 2013$ & 76 & 49 \\
3 & $00 \mathrm{~h}-08 / 11 / 2013$ & 87 & 74 \\
4 & $12 \mathrm{~h}-08 / 11 / 2013$ & 97 & 75 \\
\hline
\end{tabular}




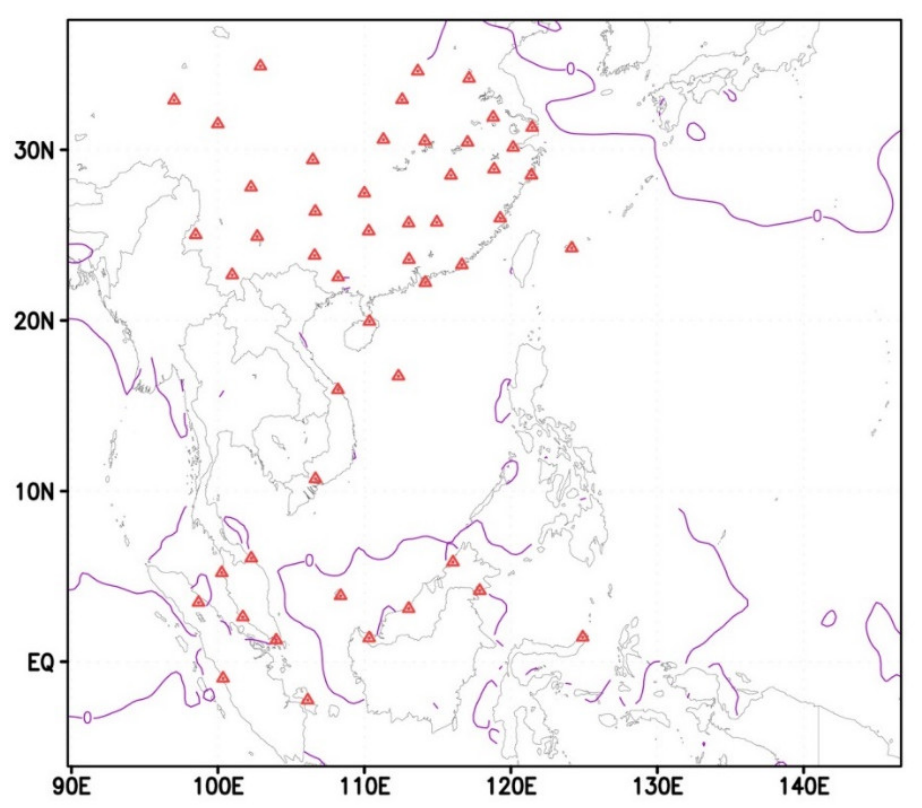

Hình 4. Vị trí các trạm cao không có số liệu đưa vào đồng hóa lúc 12 giờ UTC 07/11/2013.

\subsubsection{Tóm tắt về lọc Kalman tổ hợp}

Ý tưởng chính của thuật toán lọc Kalman tổ hợp với một biến thể lọc Kalman tổ hợp biến đổi địa phương (LETKF) là sử dụng ma trận tổ hợp nền như một toán tử chuyển đổi từ không gian mô hình được căng bởi các điểm lưới trong khu vực địa phương đã chọn sang không gian tổ hợp được căng bởi các thành phần tổ hợp, và thực hiện phân tích trong không gian tổ hợp này ở mỗi điểm lưới. Chi tiết thuật toán Kalman tổ hợp trong tài liệu [1].

Tổ hợp phân tích $\mathbf{x}^{\mathrm{a}}$ cuối cùng được thực hiện như sau:

$$
\mathbf{x}^{\mathrm{a}(\mathrm{i})}=\overline{\mathbf{x}}^{\mathrm{b}}+\mathbf{X}^{\mathrm{b}}\left\{\overline{\mathbf{w}}^{\mathrm{a}}+\left[(\mathrm{k}-1) \widehat{\mathbf{P}}^{\mathrm{a}}\right]^{1 / 2}\right\} .
$$

Trong đó ký hiệu in đậm là vector; $\bar{x}^{b}$ ma trận trung bình tổ hợp; $\mathbf{x}^{b}$ ma trận nhiễu tổ hợp; $\widehat{\mathbf{P}}^{\mathrm{a}}$ ma trận tương quan sai số phân tích và $\overline{\mathbf{w}}^{\mathrm{a}}$ là ma trận trọng số trong không gian tổ hợp.

\subsubsection{Phương pháp đánh giá}

a. Phương pháp trung bình tuyệt đối

Sai số MAE được sử dụng để đánh giá các dự báo của biến khí quyển liên tục [11]. Do vậy, MAE được áp dụng như một chỉ số để đánh giá sai số cường độ bão (Khí áp mực biển cực tiểu tại tâm-PMIN và tốc độ gió cực đại gần tâm VMAX). Với MAE-sai số trung bình tuyệt đối được tính bằng công thức:

$$
\mathrm{MAE}=\frac{1}{N} \sum_{i=1}^{N}\left|F_{i}-O_{i}\right|
$$

Trong đó MAE là sai số trung bình tuyệt đối; $F_{i}$ là giá trị dự báo; $O_{i}$ là giá trịquan trắc; $\mathrm{N}$ là độ dài chuỗi số liệu.

b. Phương pháp khoảng cách tâm bão

Sai số quỹ đạo tính theo công thức (3):

$$
P E=R_{e} * \arccos \left[\sin \left(\alpha_{1}\right) * \sin \left(\alpha_{2}\right)+\cos \left(\alpha_{1}\right) * \cos \left(\alpha_{2)} * \cos \left(\beta_{1}-\beta_{2}\right)\right]\right.
$$


Trong đó $\mathrm{R}_{\mathrm{e}}$ là bán kính trái đất $(6378,16 \mathrm{~km}) ; \alpha_{1}, \alpha_{2}$ là vĩ độ của tâm bão thực tế và tâm bão do mô hình dự báo (đv radian); $\beta_{1}, \beta_{2}$ là kinh độ của tâm bão thực tế và tâm bão dự báo (đv radian). Sai số trung bình khoảng cách được tính như sau:

$$
M P E_{j}=\frac{\sum_{i=1}^{n} P E_{i, j}}{n}
$$

Trong đó $\mathrm{PE}$ là sai số khoảng cách của từng trường hợp dự báo; $\mathrm{n}$ là số trường hợp thử nghiệm; j là hạn dự báo.

\section{Kết quả và thảo luận}

\subsection{Tác động của số liệu quan trắc đến mô phỏng đường dòng}

Do quỹ đạo bão Haiyan sau 12 giờ ngày 7/11 có sự thay đổi về hướng, nên việc dự bão quỹ đạo sẽ gặp khó khăn. Vì vậy trong nghiên cứu này nhõm tác giả tiến hành chạy các thử nghiệm dự báo hạn 3 ngày với thời điểm bắt đầu dự báo từ 00 giờ UTC ngày $7 / 11$ đến 12 giờ UTC ngày 18/11 cách nhau 6 giờ (có 6 thử nghiệm tương ứng với 84 dự báo cho một thử nghiệm). Trong phần này, để biết được tác động của số liệu quan trắc đến kết quả mô phỏng, nghiên cứu phân tích kết quả của một mô phỏng cụ thể được dự báo lúc 12 giờ UTC ngày 07 đển 12 giờ UTC ngày 10 tháng 11 năm 2013. Trong đó, nghiên cứu chỉ ra sự khác biệt trong mô phỏng hoàn lưu qui mô lớn lúc 12 giờ UTC ngày 08/11/2013, là thời điểm quỹ đạo cơn bão Haiyan chuyển từ hướng tây sang tây tây bắc. Tại thời điểm bắt đầu dự báo, số liệu quan trắc được đưa vào trường ban đầu của mô hình trong thử nghiệm CIMSS, RADS và MIX với trường gió phân tích và gió quan trắc trong một số mực được minh họa trong hình 5 , hình 6 và hình 7 .

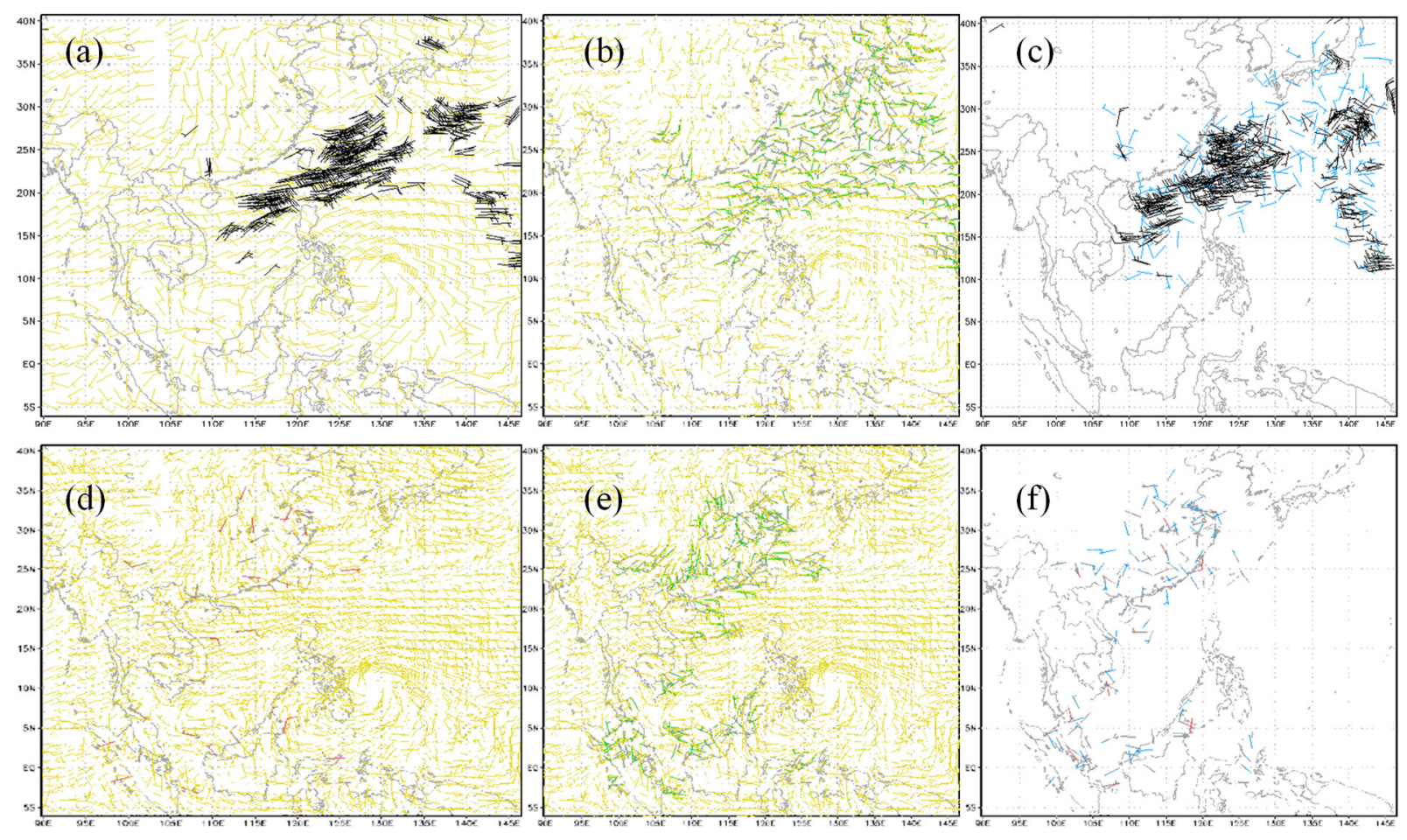

Hình 5. Trường gió ban đầu chưa đồng hóa (vectơ gió màu vàng), gió quan trắc (màu đen-gió vệ tinh; màu đỏ-gió cao không) (hình $\mathrm{a}, \mathrm{d}$ ); trường gió phân tích vệ tinh (hình $\mathrm{b}$ ) và cao không (hình $\mathrm{e}$ ); số gia trường gió phân tích (màu xanh dương) với số gia gió quan trắc (gió vệ tinh-màu đen; gió cao không-màu đỏ) (hình c,f) mực 850hPa lúc 12 giờ ngày 07/11/2013. 


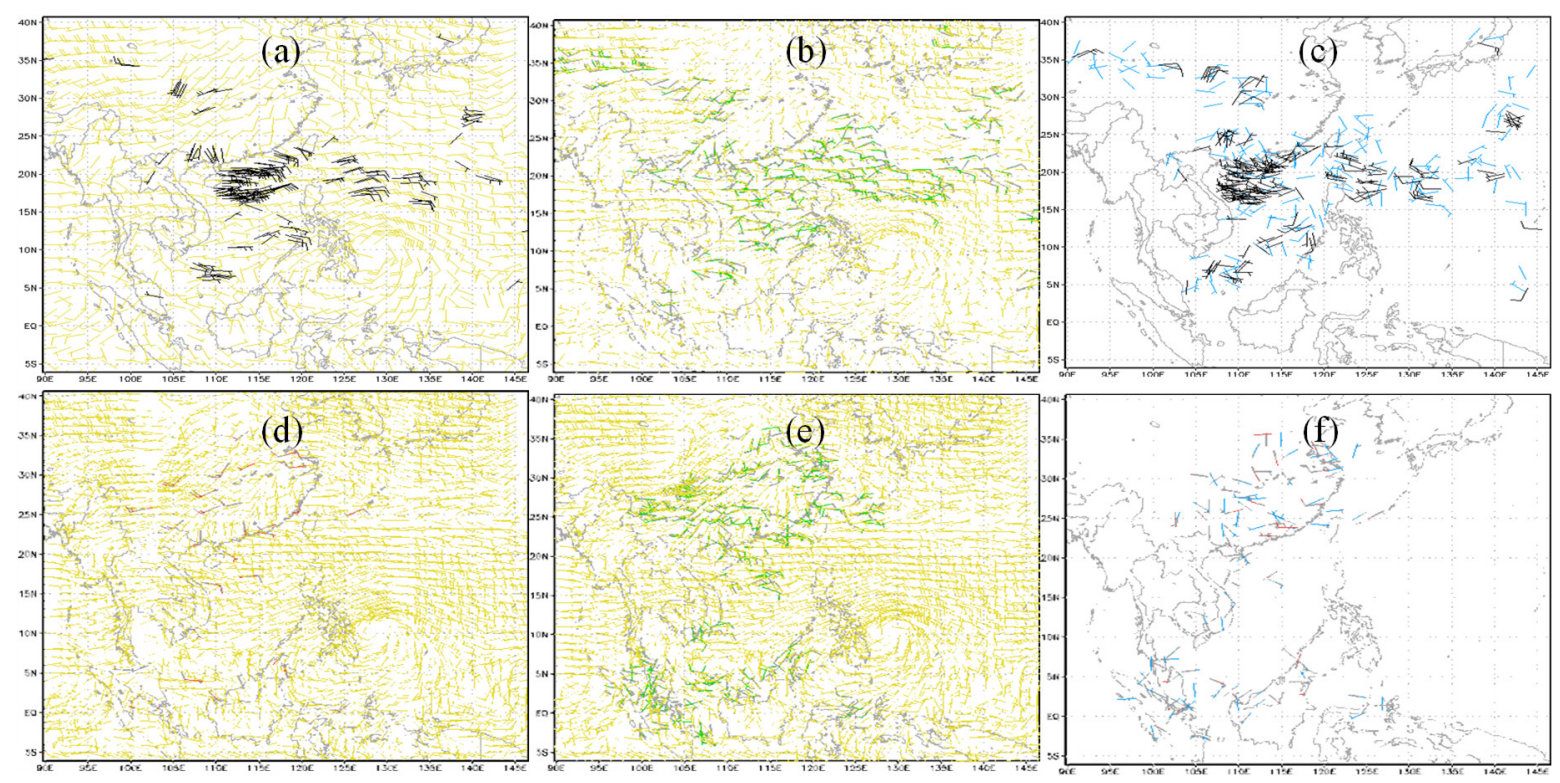

Hình 6. Trường gió ban đầu chưa đồng hóa (vectơ gió màu vàng), gió quan trắc (màu đen-gió vệ tinh; màu đỏ-gió cao không) (hình $\mathrm{a}, \mathrm{d})$ ); trường gió phân tích vệ tinh (hình $\mathrm{b}$ ) và cao không (hình e); số gia trường gió phân tích (màu xanh dương) với số gia gió quan trắc (gió vệ tinh-màu đen; gió cao không-màu đỏ) (hình c,f) mực 700 hPa lúc 12 giờ ngày 07/11/2013.

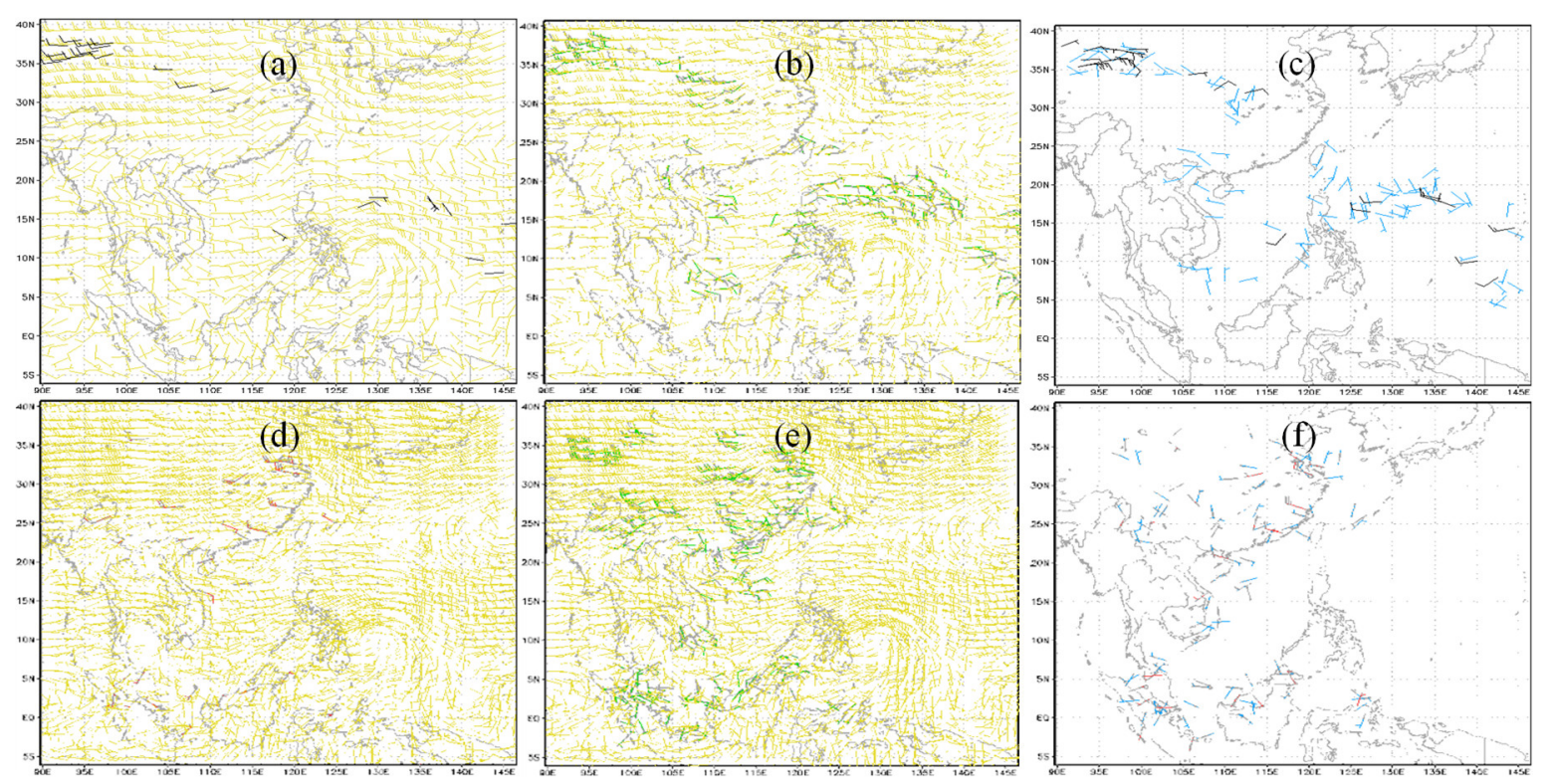

Hình 7. Trường gió ban đầu chưa đồng hóa (vectơ gió màu vàng), gió quan trắc (màu đen-gió vệ tinh; màu đỏ-gió cao không) (hình a,d); trường gió phân tích vệ tinh (hình b) và cao không (hình e); số gia trường gió phân tích (màu xanh dương) với số gia gió quan trắc (gió vệ tinh-màu đen; gió cao không-màu đỏ) (hình c,f) mực 500 hPa lúc 12 giờ ngày 07/11/2013.

Với trường đầu vào khác nhau trong các thử nghiệm MPH, CIMSS, RADS và MIX, sau 24 giờ, nghĩa là lúc 12 giờ UTC ngảy $08 / 11 / 2013$, hoàn lưu mô phỏng có sự khác biệt giữa các thử nghiệm. Điển hình ở mực $850 \mathrm{hPa}$, áp cao cận nhiệt Bắc Thái Bình Dương (NPSH) trong thử nghiệm CIMSS (hình $8 \mathrm{~b}$ ) được mô phỏng dịch lên phía bắc nhiều hơn so với vị trí áp cao cận nhiệt Bắc Thái Bình Dương trong thử nghiệm MPH, RADS và MIX (hình 8). Ở hai mực $700 \mathrm{hPa}$ và $500 \mathrm{hPa}$, hình thế xảy ra tương tự, với vị trí hoạt động của NPSH trong thử nghiệm CIMSS (hình $8 \mathrm{f}, 8 \mathrm{j}$ ) di chuyển nhiều lên phía bắc và dịch sang 
phía đông nhiều hơn so với NPSH trong thử nghiệm MPH (hình $8 \mathrm{e}, 8 \mathrm{i}$ ). Hình thế này, tạo điều kiện cho cơn bão Haiyan đổi hướng di chuyển từ tây sang bắc tây bắc.

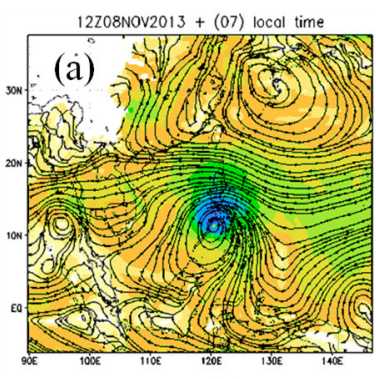

12Z08Nov2013 + (07) locol time
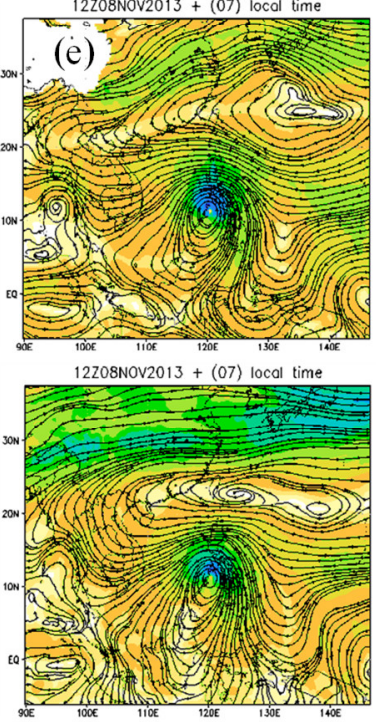

(i)

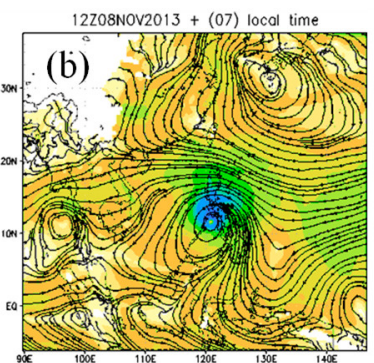

$12208 \mathrm{Nov} 2013+(07)$ local time
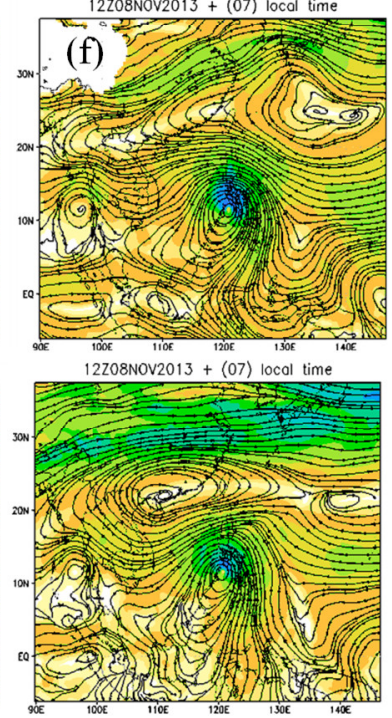

(j)

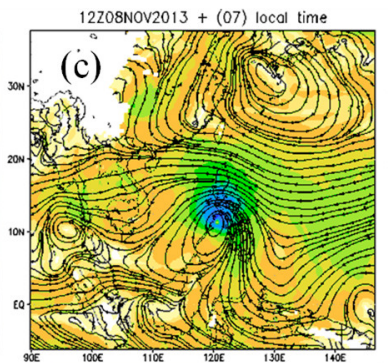

$12208 \mathrm{Nav} 2013+(07)$ local time
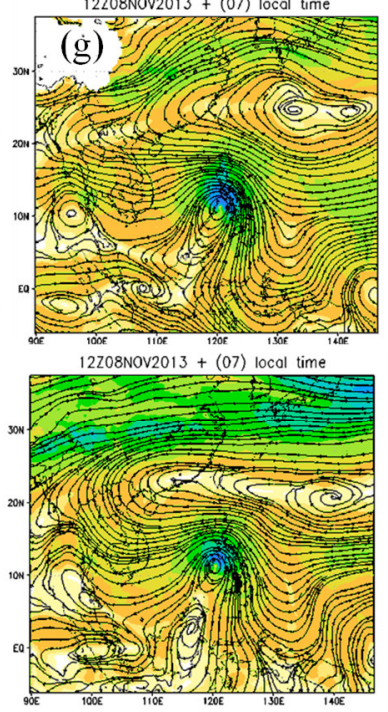

(k)

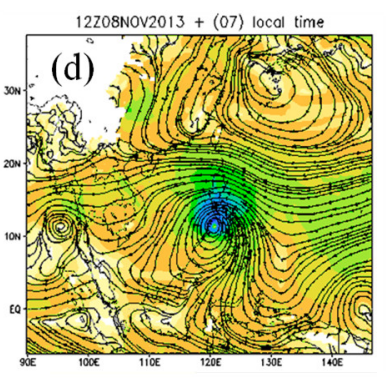

$12208 \mathrm{Nov} 2013+(07)$ local time
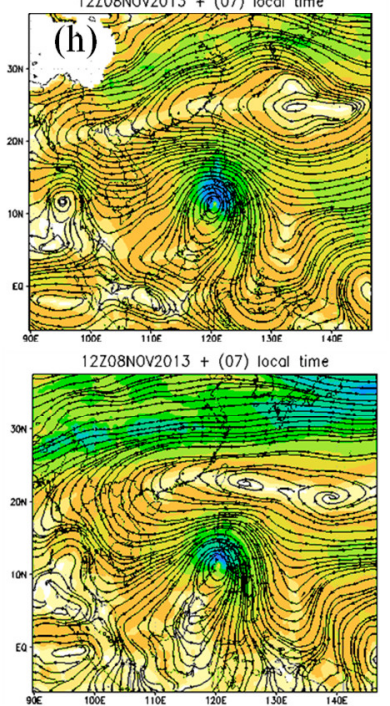

(1)

Hình 8. Bản đồ đường dòng mực 850, 700 và 500 hPa trong thử nghiệm $\mathrm{MPH}(\mathrm{a}, \mathrm{e}, \mathrm{i}), \mathrm{CIMSS}(\mathrm{b}, \mathrm{f}, \mathrm{j})$, RADS $(\mathrm{c}, \mathrm{g}, \mathrm{k})$ và MIX $(\mathrm{d}, \mathrm{h}, \mathrm{l})$ mô phỏng lúc 12 giờ UTC ngày 08 . Và độ lớn tốc độ gió ở mực tương ứng.

Sau 48 giờ, nghĩa là lúc 12 giờ UTC ngày 09/11/2013, trên mực $850 \mathrm{hPa}$ thử nghiệm CIMSS (hình 9b) mô phỏng NSPH rút về phía đông nhanh hơn so với NSPH được mô phỏng trong thử nghiệm $\mathrm{MPH}, \mathrm{RADS}$ và $\mathrm{MIX}$ (hình $9 \mathrm{a}, 9 \mathrm{c}$, và $9 \mathrm{~d}$ ). Hình thế này được mô phỏng tương tự quan trắc. Do đó, nó tạo điều kiện cho cơn bão Haiyan di chuyển theo hướng bắc tây bắc trong thử nghiệm CIMSS, nghĩa là tương đồng với quỹ đạo thực của nó. Hình thế tương tự xảy ra ở mực $700 \mathrm{hPa}$ và $500 \mathrm{hPa}$.

Sau 72 giờ, kết quả mô phỏng lúc 12 giờ UTC ngày 10/11 (hình 10), ở mực 850hPa thử nghiệm MPH (hình 10a) mô phỏng rãnh gió tây ở phía bắc phát triển sâu xuống phía nam hơn so với rãnh gió tây trong các thử nghiệm CIMSS, RADS và MIX (hình $10 \mathrm{~b}, \mathrm{c}, \mathrm{d}$ ), do đó trong thử nghiệm $\mathrm{MPH}$, hình thế này đã khống chế cơn bão Haiyan di chuyển theo hướng tây bắc khác với hướng di chuyển bắc tây bắc của quỹ đạo thực. Trong khi đó, thử nghiệm RADS và thử nghiệm MIX mô phỏng rãnh gió tây lấn xuống phía nam nhiều hơn so với thử nghiệm CIMSS, vì vậy vị trí tâm bão ở hạn dự báo này của 2 thử nghiệm RADS và MIX xa vị trí tâm bão thực tế hơn vị trí tâm bão trong thử nghiệm CIMSS. Ở mực $700 \mathrm{hPa}$ và $500 \mathrm{hPa}$, thử nghiệm CIMSS (hình 10f), bão Haiyan đang di chuyển theo hướng bắc tây bắc và chịu ảnh hưởng của rìa phía tây của áp cao cận nhiệt đới Bắc Thái Bình Dương yếu hơn và có tâm lệch về phía bắc nhiều hơn so với vị trí áp cao cận nhiệt đới Bắc Thái Bình Dương trong thử nghiệm MPH, RADS và MIX (hình $10 \mathrm{e}, \mathrm{g}, \mathrm{h}$ ). Ngoài ra thử nghiệm RADS và MIX cũng mô phỏng áp cao cận nhiệt đới Bắc Thái Bình Dương yếu hơn và có hoàn lưu mở rộng sang tây 
nam ít hơn so với thử nghiệm MPH. Hình thế này giải thích cho quỹ đạo dịch chuyển của cơn bão Haiyan trong thử nghiệm CIMSS, RADS và MIX sát với quỹ đạo thực của cơn bão Haiyan hơn so với thử nghiệm MPH ở hạn dự báo này(hướng di chuyển bắc tây bắc).
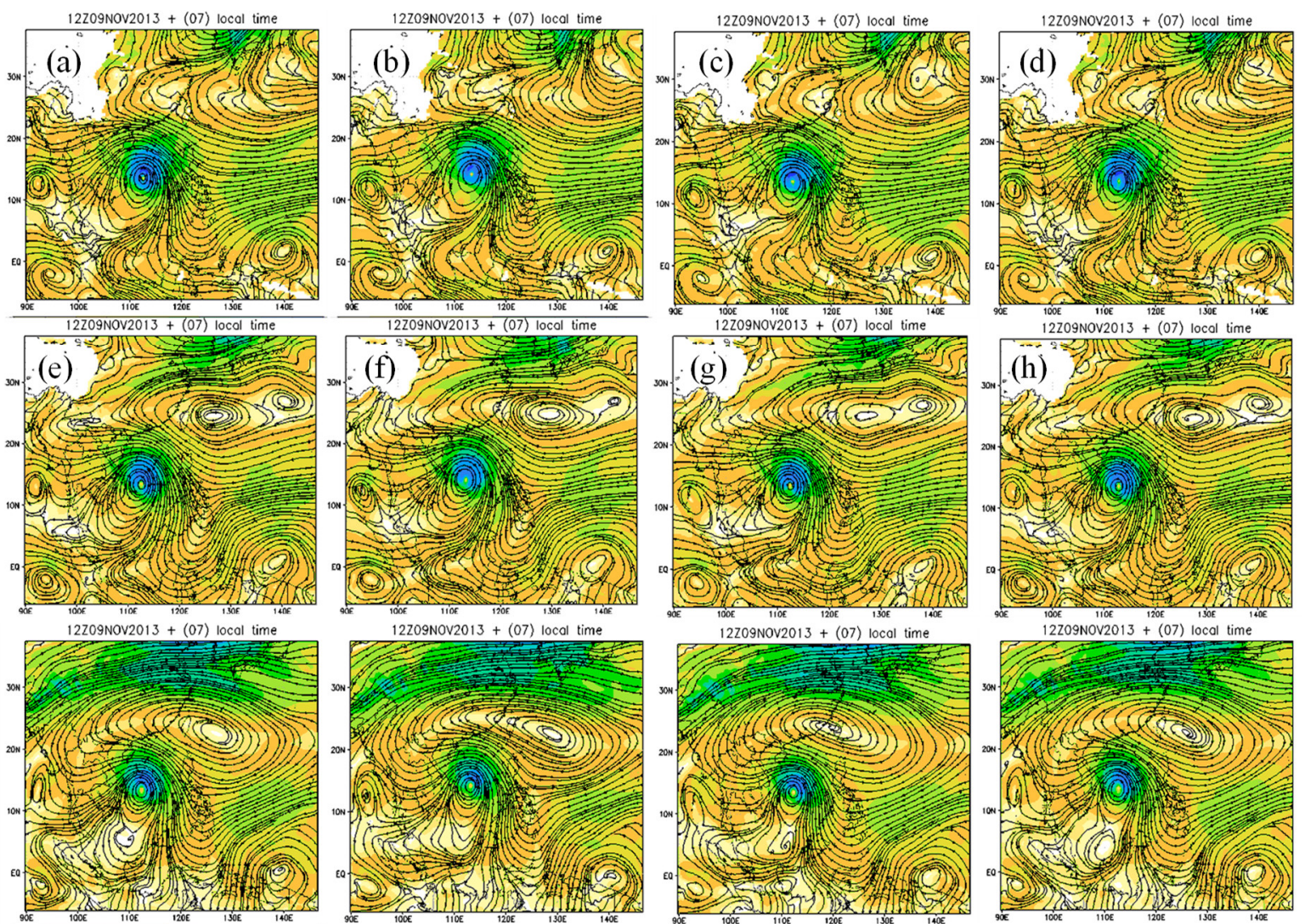

2209NOV2013 + (07) local time

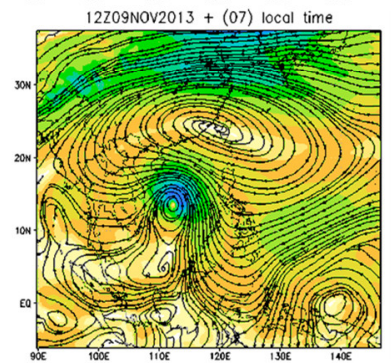

(k)

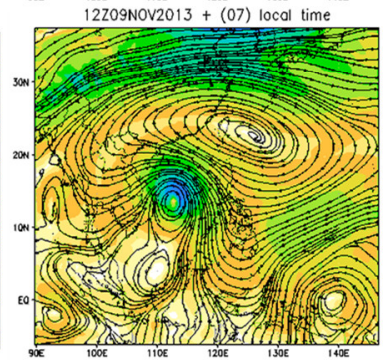

(l)

Hình 9. Bản đồ đường dòng mực $850 \mathrm{hPa}, 700 \mathrm{hPa}, 500 \mathrm{hPa}$ trong thử nghiệm $\mathrm{MPH}(\mathrm{a}, \mathrm{e}, \mathrm{i}), \mathrm{CIMSS}$ $(b, f, j), \operatorname{RADS}(\mathrm{c}, \mathrm{g}, \mathrm{k})$ và MIX $(\mathrm{d}, \mathrm{h}, \mathrm{l})$ mô phỏng lúc 12 giờ UTC ngày 09 . Và độ lớn tốc độ gió ở mực tương ứng.

Như vậy, hoàn lưu mô phỏng trong thử nghiệm CIMSS, RADS và MIX không giống với hoàn lưu thực tế. Nhưng về xu hướng phát triển hoàn lưu (sự mở rộng hoặc di chuyển của các hệ thống quy mô lớn) trong thử nghiệm CIMSS RADS và MIX dường như gần với xu hướng phát triển hoàn lưu thực tế hơn so với mô phỏng hoàn lưu trong thử nghiệm $\mathrm{MPH}$ ở các hạn dự báo dài hơn 2 ngày. Đặc biệt, thử nghiệm CIMSS cho kết quả mô phỏng hoàn lưu gần với quan trắc thực tế hơn so với các thử nghiệm còn lại ở hầu hết các hạn dự báo. Kết quả này cho thấy số liệu gió quan trắc từ vệ tinh có ảnh hưởng tích cực trong việc mô phỏng hoàn lưu quy mô lớn trong mô hình số. Trong phần tiếp theo, nghiên cứu trình bày một số kết quả mô phỏng quỹ đạo và cường độ cơn bão Haiyan.

\subsection{Tác động của số liệu quan trắc đến mô phỏng qũy đạo bão}

Hình 11 là quỹ đạo cơn bão Haiyan quan trắc (màu xanh lá cây) và quỹ đạo dự báo trung bình (MPH-màu đỏ, CIMSS-màu đen, RADS-xanh da trời, MIX-xanh dương và quỹ đạo dự báo của mô hình toàn cầu GFS (màu hồng), bắt đầu mô phỏng từ 12 giờ ngày 07 tháng 11 năm 2013 và kết thúc lúc 12 giờ ngày 10 tháng 11 . Trong 24 giờ đầu tiên, quỹ đạo mô phỏng và quỹ đạo thực của cơn bão Haiyan đều di chuyển theo hướng tây trong các thử nghiệm. Nhưng bắt đầu từ 12 giờ UTC ngày 08 đến 12 giờ UTC ngày 09/11/2013, quỹ đạo bão thực tế và quỹ đạo bão mô phỏng của các thử nghiệm di chuyển theo hướng tây bắc. Trong đó, thử 
nghiệm MPH, RADS, MIX và GFS lệch tây nhiều hơn so với qũy đạo thực. Sự khác biệt trong mô phỏng quỹ đạo bão Haiyan trong các thử nghiệm trên là do sự tiến triển của hoàn lưu quy mô lớn (áp cao cận nhiệt đới Bắc Thái Bình Dương) như đã phân tích ở phần 3.1.1.

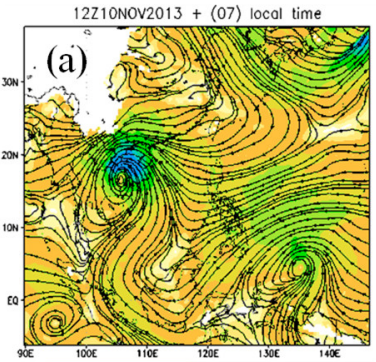

12210 Nav2013 + (07) local time

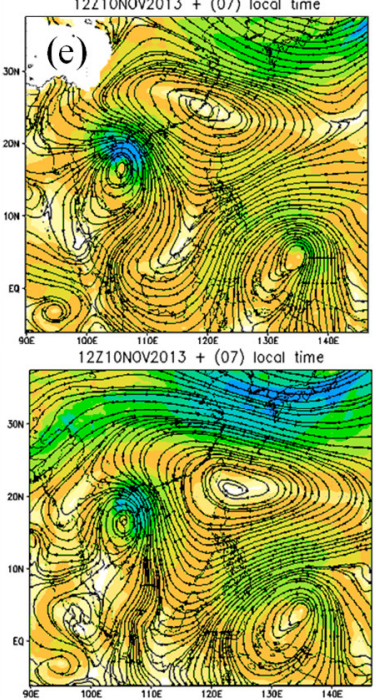

(i)

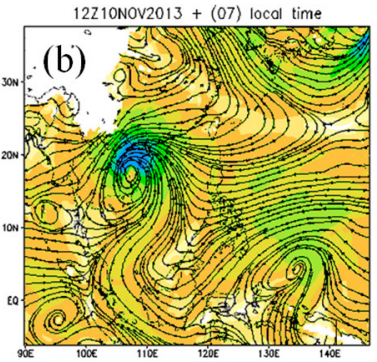

12210 Nov2013 + (07) locol time
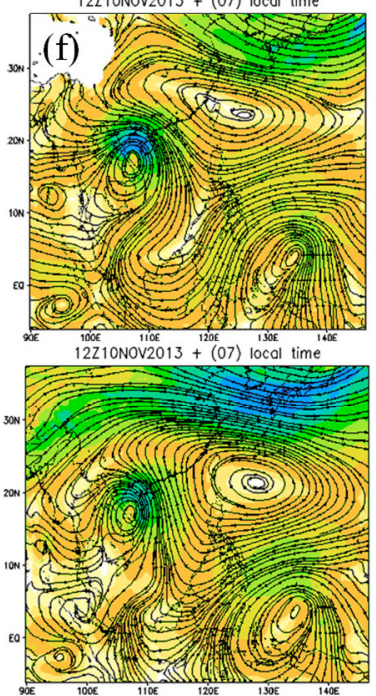

(j)

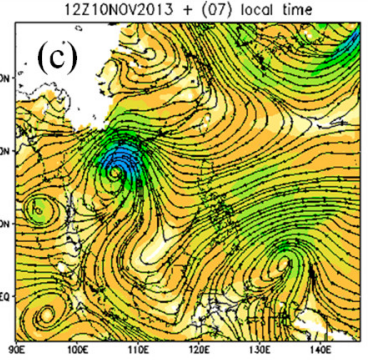

12210 Nov2013 + (07) local time
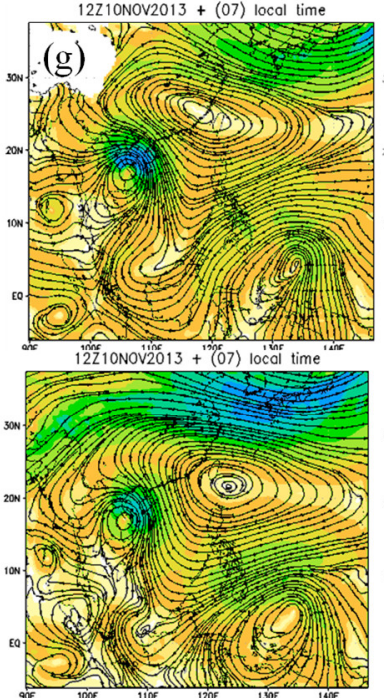

(k)
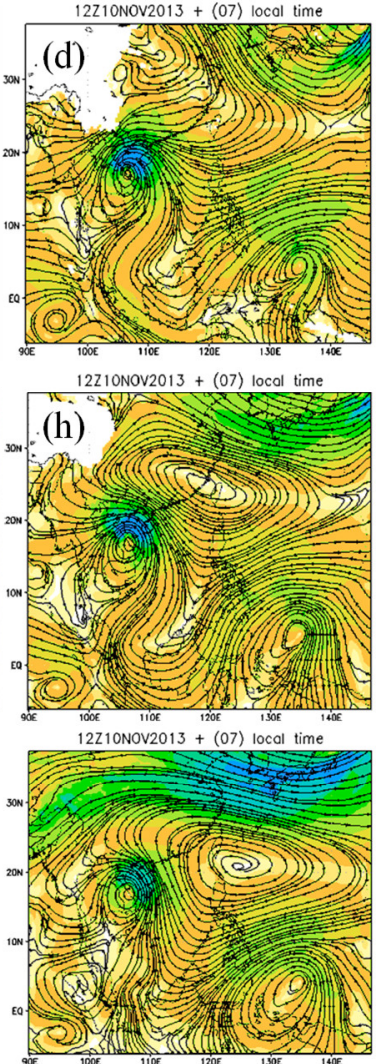

(l)

Hình 10. Bản đồ đường dòng mực $850 \mathrm{hPa}, 700 \mathrm{hPa}, 500 \mathrm{hPa}$ trong thử nghiệm $\mathrm{MPH}(\mathrm{a}, \mathrm{e}, \mathrm{i}), \mathrm{CIMSS}$ $(\mathrm{b}, \mathrm{f}, \mathrm{j}), \operatorname{RADS}(\mathrm{c}, \mathrm{g}, \mathrm{k})$ và MIX $(\mathrm{d}, \mathrm{h}, \mathrm{l})$ mô phỏng lúc 12 giờ UTC ngày 10 . Và độ lớn tốc độ gió ở mực tương ứng.

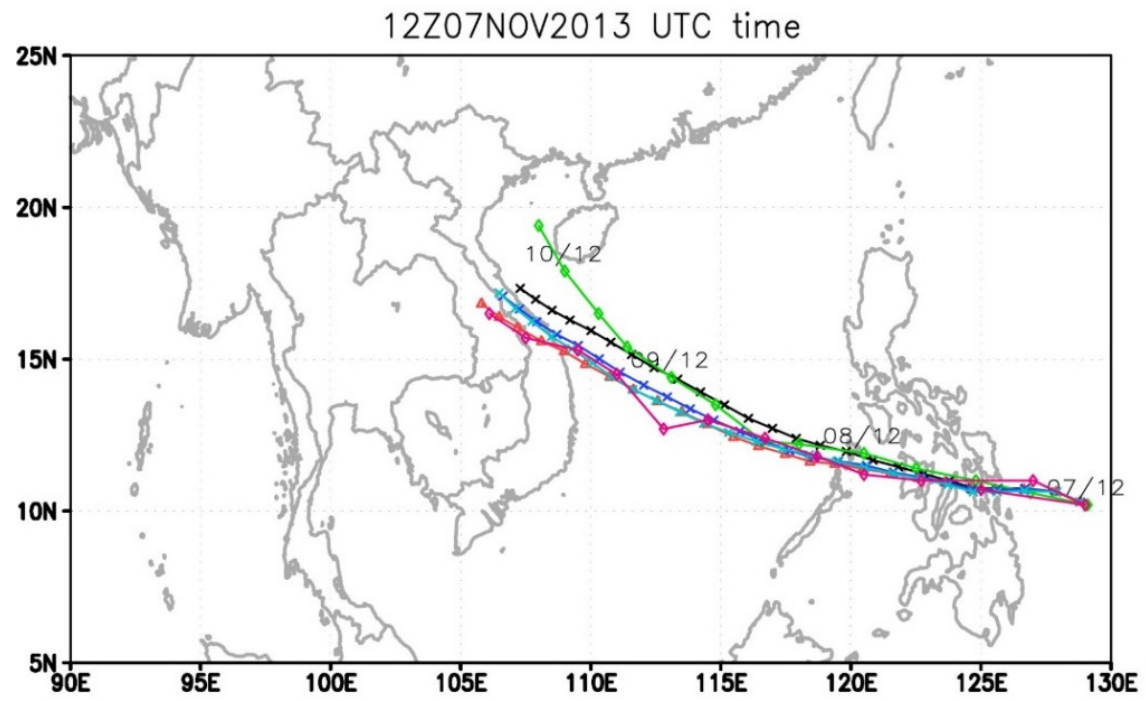

Hình 11. Quỹ đạo bão quan trắc (màu xanh lá), quỹ đạo bão trong thử nghiệm MPH (màu đỏ), quỹ đạo bão trong thử nghiệm CIMSS (màu đen), quỹ đạo bão trong thử nghiệm RADS (màu xanh da trời), quỹ đạo bão trong thử nghiệm MIX (màu xanh dương) và quỹ đạo bão với số liệu dự báo toàn cầu GFS (màu hồng) của cơn bão Haiyan 2013. Thời điểm bắt đầu dự báo 12 giờ ngày 07/11/2013. 
Từ 12 giờ UTC ngày 09/11 đến 12 giờ UTC ngày 10/11, quỹ đạo thực của cơn bão Haiyan đã chuyển hướng di chuyển sang bắc tây bắc. Trong khi đó, mô phỏng quỹ đạo của các thử nghiệm vẫn di chuyển theo hướng tây bắc. Nhưng xét quỹ đạo bão trong mô phỏng của thử nghiệm CIMSS vẫn gần sát với quỹ đạo thực của cơn bão Haiyan hơn so với quỹ đạo bão được mô phỏng trong các thử nghiệm còn lại. Kết quả này cũng có thể được giải thích do sự ảnh hưởng của số liệu gió quan trắc từ vệ tịnh đã tác động đến mô phỏng hoàn lưu trong thử nghiệm CIMSS nên có sự tiến triển tương tự như hình thế synop thực tế. Đặc biệt vào hạn dự báo 48 giờ và 72 giờ, sai số dự báo quỹ đạo bão trong thử nghiệm CIMSS lần lượt là 50 $\mathrm{km}$ và $240 \mathrm{~km}$, giảm đáng kể so với các thử nghiệm còn lại (hình 12). Ngoài ra sai số qũy đạo bão trong các thử nghiệm RADS, MIX và MPH nhỏ hơn sai số quỹ đạo GFS ở hạn dự báo 72 giờ. Mặt khác, kết quả thống kê tính trung bình sai số dự báo quỹ đạo bão Haiyan trong 4 trường hợp mô phỏng (từ 00 giờ UTC ngày $07 / 11 / 2013$ đến 12 giờ UTC ngày $08 / 11 / 2013$ ) cũng cho thấy sai số dự báo quỹ đạo trong thử nghiệm CIMSS giảm đáng kể so với sai số dự báo quỹ đạo bão Haiyan trong các thử nghiệm còn lại và số liệu dự báo toàn cầu GFS. Cụ thể, ở hạn 24 giờ, 48 giờ và 72 giờ sai số dự báo quỹ đạo bão trong thử nghiệm CIMSS lần lượt là $75 \mathrm{~km}, 150 \mathrm{~km}$ và $270 \mathrm{~km}$, còn thử nghiệm MPH là $90 \mathrm{~km}, 200 \mathrm{~km}$ và $360 \mathrm{~km}$, còn số liệu dự báo toàn cầu GFS lần lượt là $80 \mathrm{~km}, 200 \mathrm{~km}$ và $440 \mathrm{~km}$ (hình 13), trong khi các thử nghiệm RADS và MIX chỉ cải thiện hơn so với sai số của GFS ở hạn 72 giờ.

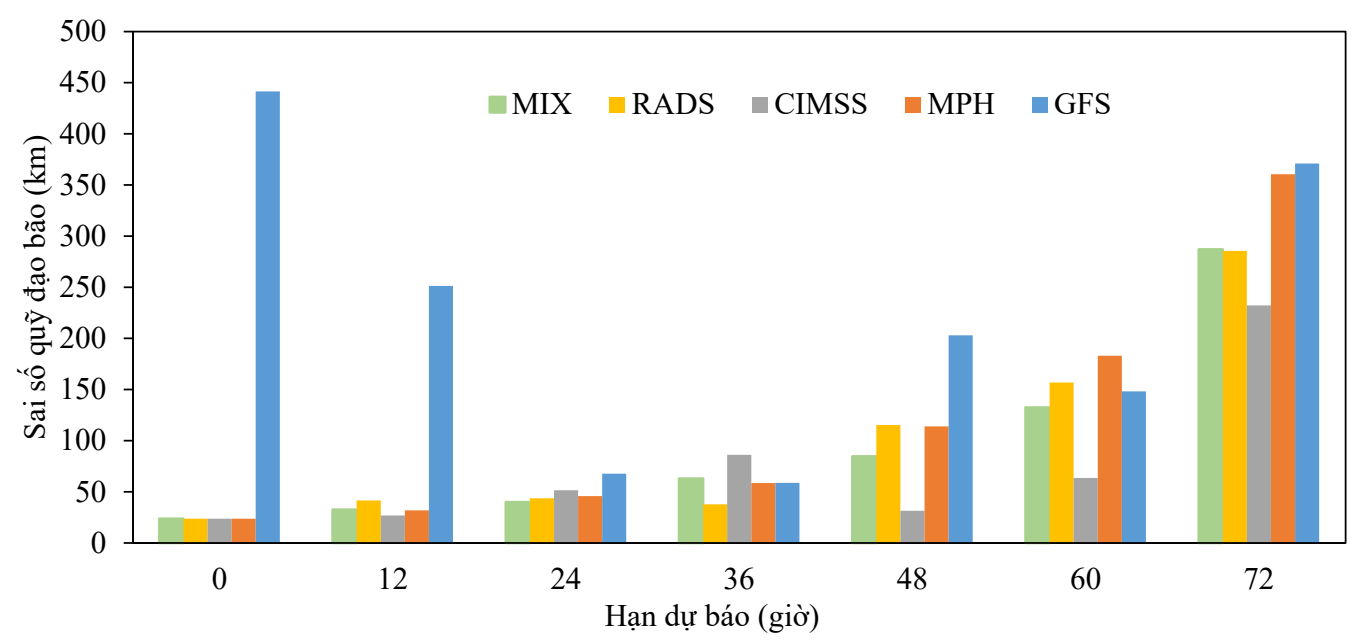

Hình 12. Sai số quỹ đạo bão trung bình của các thử nghiệm. Dự báo lúc 12 giờ UTC ngày $07 / 11 / 2013$.

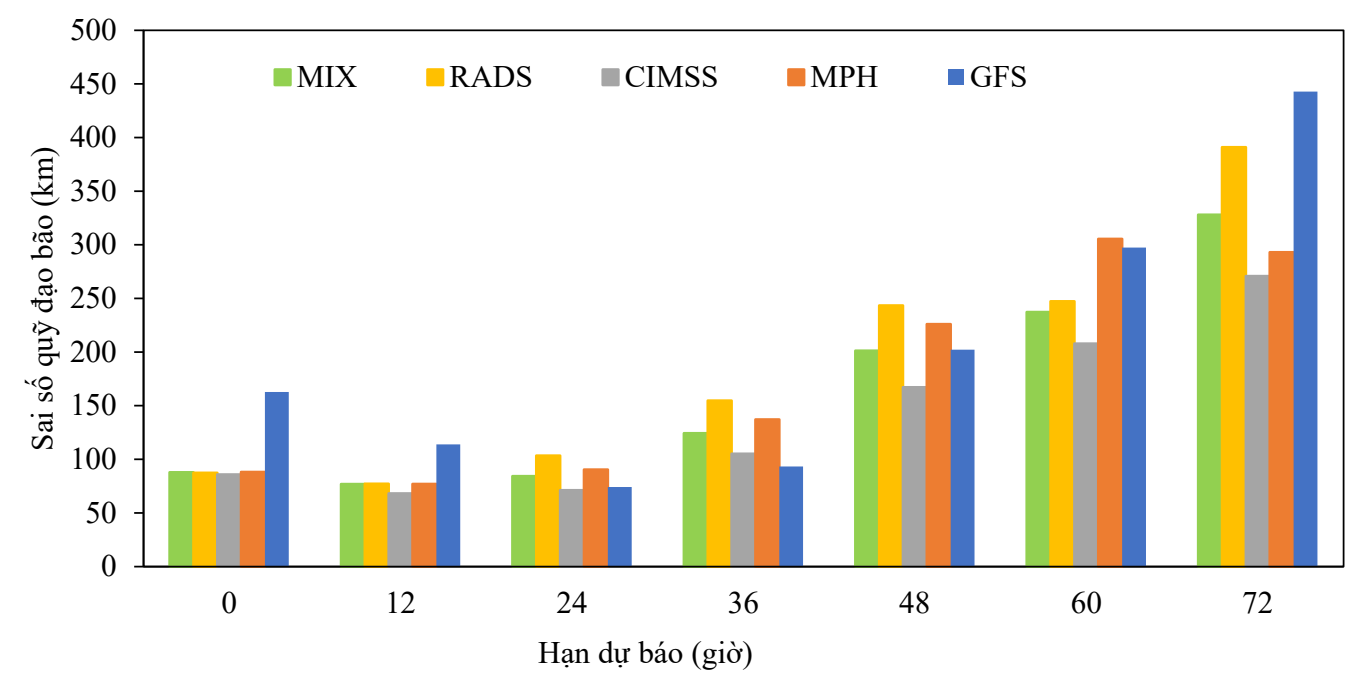

Hình 13. Đánh giá sai số trung bình quỹ đạo mô phỏng trong 4 trường hợp. 


\subsection{Tác động của số liệu quan trắc đến mô phỏng cuờng độ bão Haiyan}

Cường độ bão được thể hiện qua giá trị khí áp mực biển cực tiểu tại tâm bão (Pmin) và tốc độ gió bề mặt cực đại gần tâm (Vmax). Các giá trị Pmin và Vmax được tính trung bình cho 21 thành phần dự báo trong các thử nghiệm.

\subsubsection{Khí áp mực biển cực tiểu tại tâm}

Hình 14 cho thấy biến trình khí áp cực tiểu tại tâm quan trắc (màu xanh da trời), Pmin trong các mô phỏng và Pmin trong số liệu dự báo toàn cầu GFS, về xu thế, từ 42 giờ đến 72 giờ, mô phỏng Pmin trong các thử nghiệm có biến trình tương tự như quan trắc, đặc biệt càng về hạn dự báo 72 giờ Pmin trong thử nghiệm CIMSS càng gần với quan trắc, trong khi Pmin do GFS mô phỏng cao hơn quan trắc và các thử nghiệm. Trước hạn dự báo 42 giờ, Pmin trong các thử nghiệm hầu hết không mô phỏng được xu thế của Pmin thực tế. Về độ lớn của Pmin trong các thử nghiệm có thể đánh giá rõ hơn thông qua sai số trung bình tuyệt đối (hình 15).

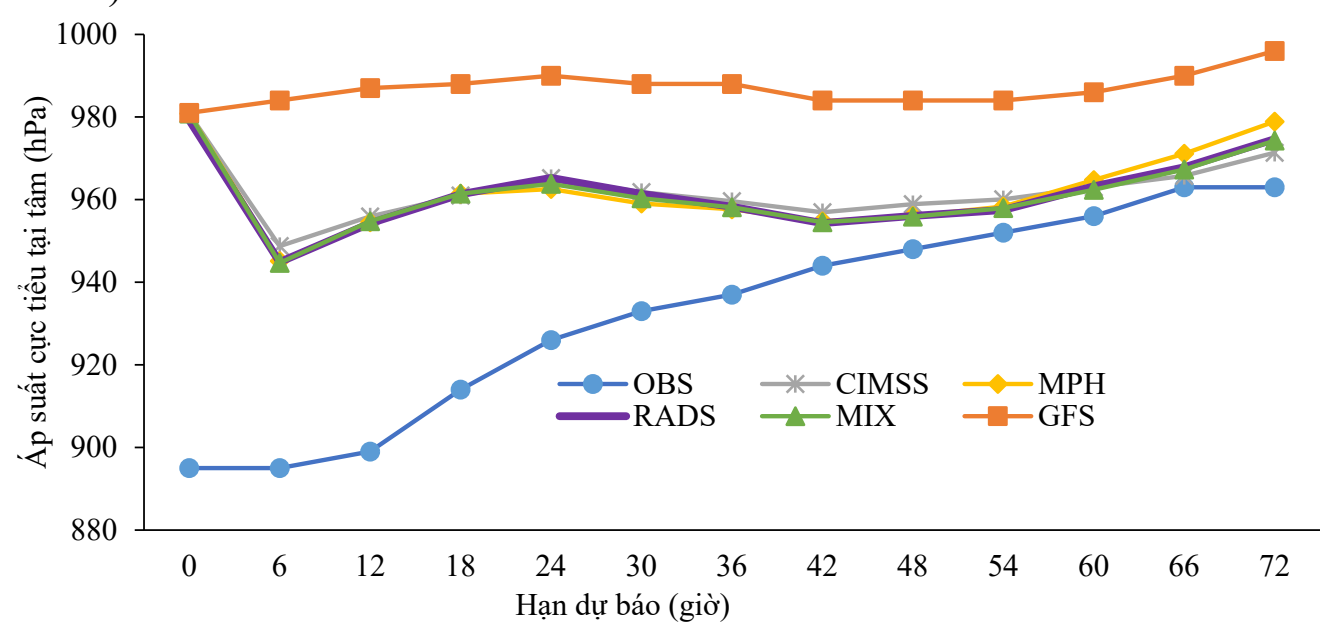

Hình 14. Biến trình Pmin trung bình trong các thử nghiệm. Với thời điểm bắt đầu dự báo lúc 12 giờ UTC ngày $07 / 11 / 2013$.

Hình 15 cho thấy sai số Pmin trong các thử nghiệm đều nhỏ hơn sai số Pmin của số liệu dự báo toàn cầu GFS ở tất cả các hạn dự báo. Trong 12 giờ đầu tiên, sai số dự báo Pmin khá lớn cả ở số liệu GFS và các thử nghiệm. Sai số lớn này là do số liệu GFS có độ phân giải thô nên Pmin được mô phỏng trong số liệu GFS yếu. Do đó, phải mất một khoảng thời gian để xoáy mô hình thích ứng với dòng môi trường trước khi xoáy đó phát triển phù hợp với cơ chế động lực [5]. Thông thường để khắc phục nhược điểm này, bài toán cài xoáy giả (ban đầu hóa xoáy) cho thời điểm ban đầu dự báo bão được áp dụng. Kết quả này phù hợp với các nghiên cứu trước đây về lọc Kalman tổ hợp ứng dụng dự báo bão [5, 12], nghĩa là lọc Kalman tổ hợp đồng hóa số liệu gió vệ tinh chỉ cải thiện trường hoàn lưu quy mô lớn, nhờ đó kết quả dự báo quỹ đạo cũng như cường độ bão được cải thiện đáng kể sau hạn dự báo 24 giờ, còn sai số ban đầu của dự báo cường độ không cải thiện, ngoại trừ xoáy giả được cài vào trường ban đầu. Sau 24 giờ đầu tiên, sai số Pmin trong các thử nghiệm bắt đầu giảm đáng kể, đặc biệt là sau 42 giờ đến 72 giờ sai số Pmin giảm xuống dưới $10,0 \mathrm{hPa}$, đáng chú ý hơn cả là là ở hạn 72 giờ, sai số Pmin trong thử nghiệm CIMSS chỉ là $8,4 \mathrm{hPa}$, còn sai số Pmin trong thử nghiệm RADS và MIX đều sấp xỉ $10 \mathrm{hPa}$. 


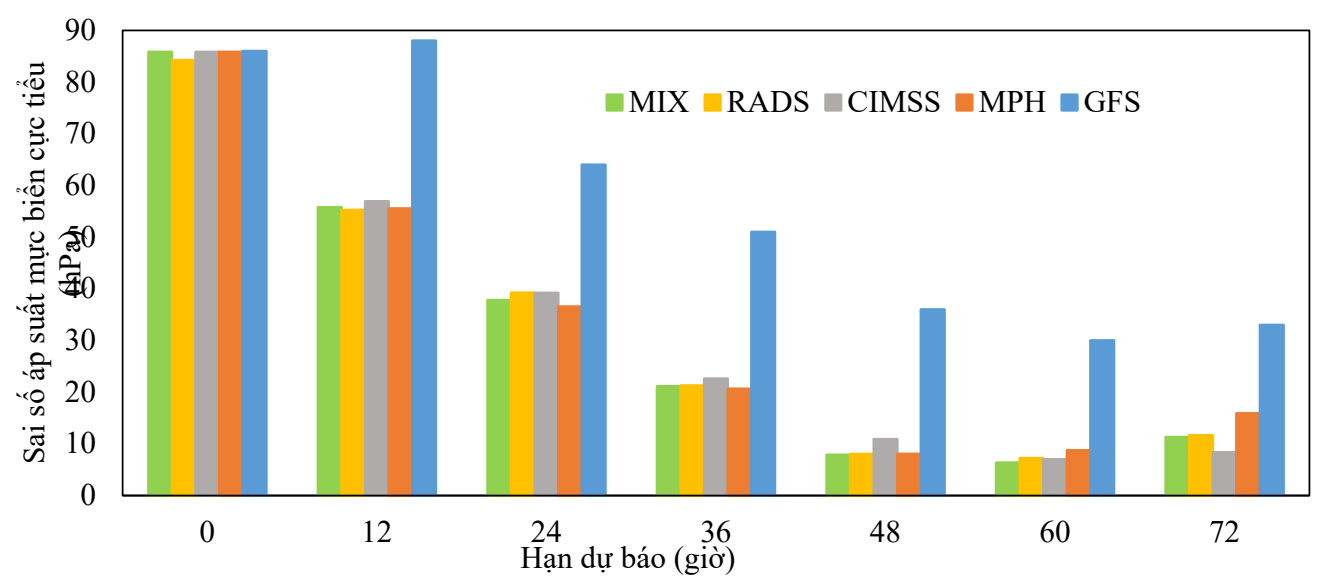

Hình 15. Sai số tuyệt đối Pmin của cơn bão Haiyan mô phỏng lúc 12 giờ UTC ngày 07/11/2013.

Tuy nhiên, đánh giá thống kê sai số Pmin trong 4 trường hợp mô phỏng (hình 16) lại cho thấy các thử nghiệm mô phỏng Pmin hiệu quả ở hầu hết các hạn dự báo so với kết quả dự báo toàn cầu GFS. Kết quả này cho thấy, việc đồng hóa số liệu quan trắc vào trường đầu vào của mô hình cải thiện đáng kể chất lượng dự báo Pmin. Ngoài ra, ở hạn dự báo dài hơn 48 giờ sai số Pmin trong các thử nghiệm CIMSS, RADS và MIX lại nhỏ hơn sai số Pmin trong thử nghiệm MPH, đặc biệt sai số Pmin trong thử nghiệm CIMSS lại nhỏ hơn sai số Pmin trong thử nghiệm RADS và MIX. Kết quả này, phần nào cho thấy hiệu quả của phương pháp lọc Kalman tổ hợp đồng hóa số liệu quan trắc trong dự báo Pmin của cơn bão Haiyan, đặc biệt là đối với số liệu gió vệ tinh, hơn nữa việc dự báo chính xác quỹ đạo bão cũng phần nào cải thiện kết quả dự báo Pmin [12]. Phần tiếp theo, nghiên cứu khảo sát tác động của số liệu quan trắc trong mô phỏng tốc độ gió cực đại gần tâm bão (Vmax).

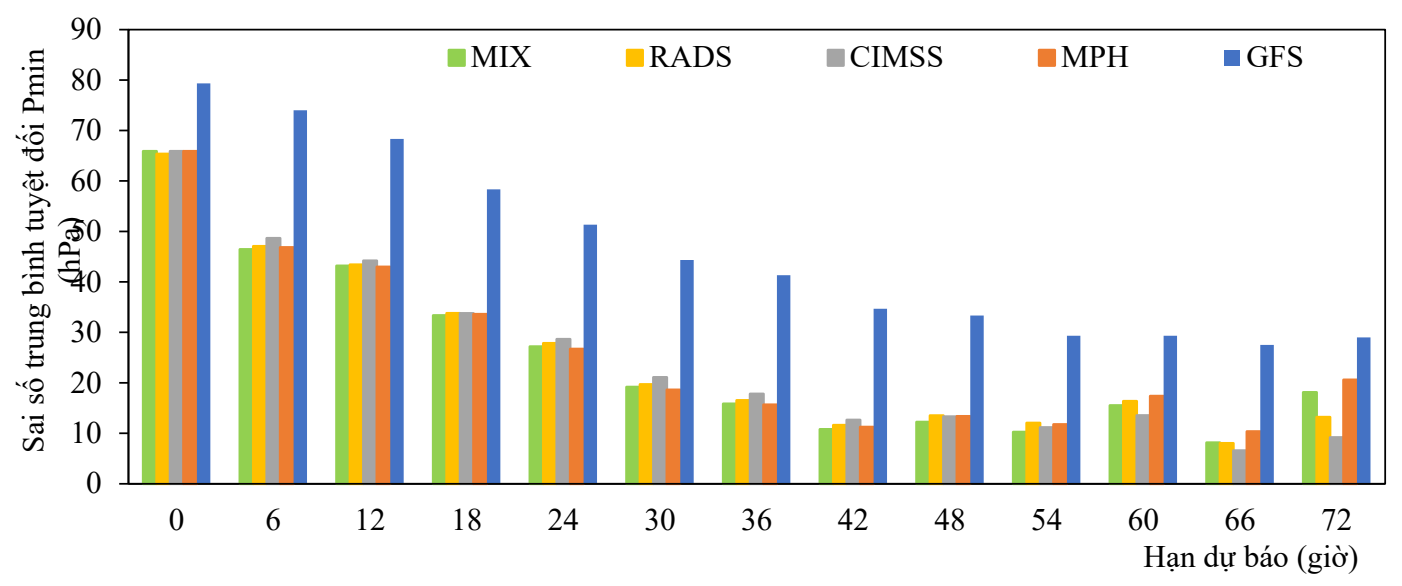

Hình 16. Đánh giá thống kê sai số trung bình Pmin mô phỏng trong 4 trường hợp.

\subsubsection{Tốc độ gió cực đại gần tâm}

Hình 17 cho thấy, biến trình Vmax trong các thử nghiệm tương đồng với biến trình Vmax quan trắc từ hạn 36 giờ đến 72 giờ. Trước hạn dự báo 36 giờ hầu hết các thử nghiệm không mô phỏng được biến trình của Vmax quan trắc. Còn Vmax trong số liệu dự báo toàn cầu hầu như không mô phỏng được biến trình $V \max$. Sự khác biệt về biến trình Vmax được thể hiện rõ hơn thông qua sai số tuyệt đối của $V \max$ (hình 18). Hình 18 là kết quả sai số tuyệt đối Vmax dự báo 3 ngày với thời điểm dự báo là lúc 12 giờ UTC ngày 07/11/2013. Trong đó, các thử nghiệm MPH, CIMSS, RADS và MIX cho kết quả sai số được cải thiện đáng kể so với số liệu dự báo toàn cầu GFS ở hầu hết các hạn dự báo. Đặc biệt, từ hạn dự báo 48 giờ đến hạn dự báo 72 giờ các thử nghiệm trên cho sai số Vmax đều dưới $5 \mathrm{~m} / \mathrm{s}$. Riêng hạn dự báo 72 giờ các thử nghiệm CIMSS, RADS và MIX có sai số Vmax nhỏ hơn sai số Vmax của thử 
nghiệm MPH. Kết quả tính sai số tuyệt đối trung bình Vmax trong 4 trường hợp mô phỏng cũng cho thấy thử nghiệm CIMSS, RADS và MIX dự báo hiệu quả Vmax ở hạn 60 giờ và 72 giờ (hình 19). Như vậy, có thể thấy số liệu quan trắc tác động đáng kể đến việc mô phỏng Vmax của cơn bão Haiyan. Trong đó số liệu gió quan trắc từ vệ tinh có tác động tích cực trong hạn dự báo 72 giờ.

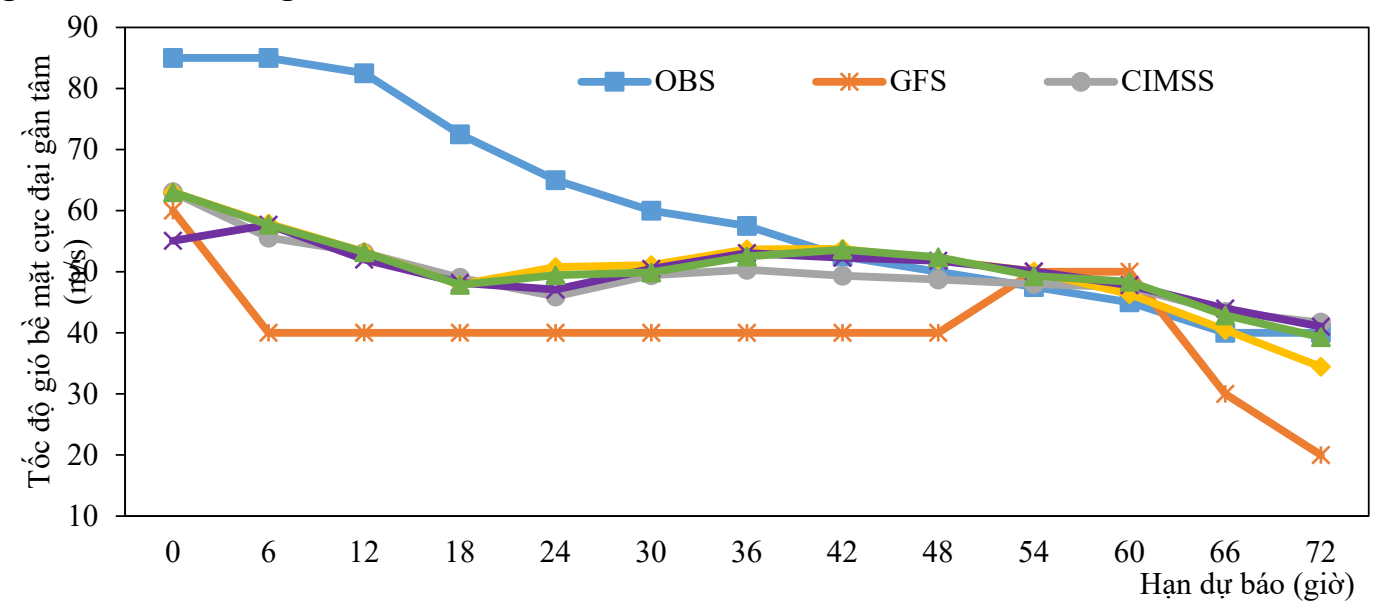

Hình 17. Biến trình Vmax trung bình của bão Haiyan trong các trường hợp thử nghiệm và quan trắc. Dự báo lúc 12 giờ UTC ngày 07/11/2013.

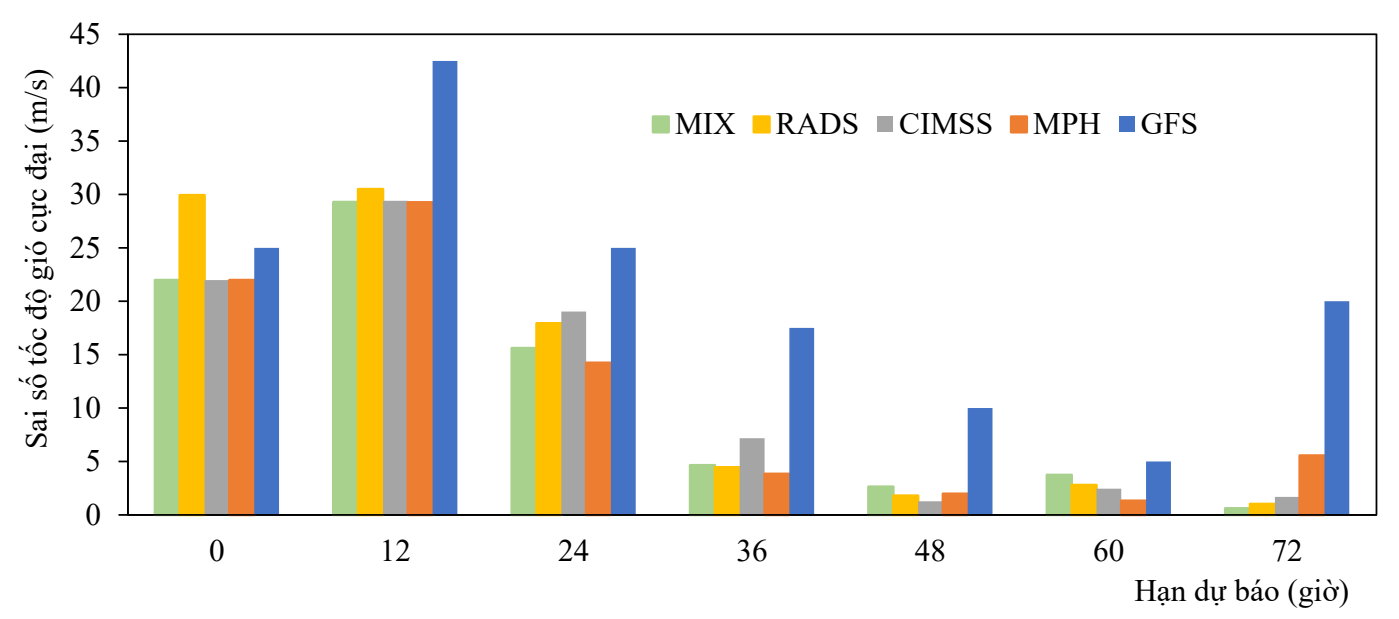

Hình 18. Sai số tuyệt đối Vmax của cơn bão Haiyan mô phỏng lúc 12 giờ UTC ngày 07/11/2013.

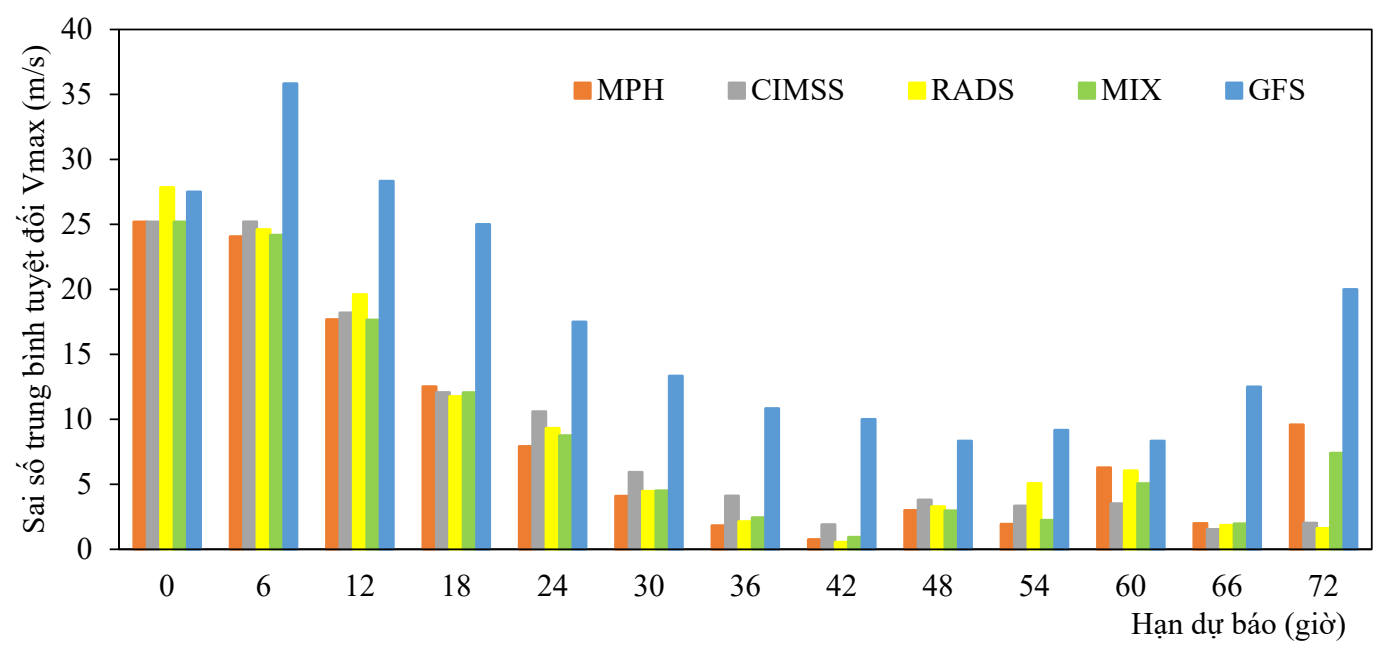

Hình 19. Đánh giá thống kê sai số tuyệt đối trung bình Vmax mô phỏng trong 4 trường hợp. 


\section{Kết luận}

Từ những kết quả thử nghiệm và đánh giá về quỹ đạo và cường độ của cơn bão Haiyan với thời gian mô phỏng bắt đầu từ 12 giờ ngày 7/11/2013, kết thúc lúc 12 giờ ngày 10/11/2013 bằng phương pháp lọc Kalman tổ hợp đồng hóa số liệu gió vệ tinh, số liệu cao không và số liệu hỗn hợp (gió vệ tinh và cao không) trong mô hình WRF, cho thấy các thử nghiệm có bổ sung số liệu quan trắc tác động tích cực đến việc mô phỏng hoàn lưu qui mô lớn (áp cao cận nhiệt đới) cả về xu thế lẫn cường độ. Nhờ đó sai số quỹ đạo bão được cải thiện đáng kể so với thử nghiệm không có số liệu quan trắc $(\mathrm{MPH})$ và số liệu dự báo toàn cầu GFS. Cụ thể, sai số quỹ đạo trong thử nghiệm CIMSS cải thiện $14,0 \%$ và $14,3 \%$ so với thử nghiệm $\mathrm{MPH}$, và giảm lần lượt $14,0 \%$ và $23,9 \%$ so với kết quả dự báo toàn cầu GFS, sai số quỹ đạo trong thử nghiệm RADS cải thiện $11,1 \%$ so với GFS và MPH ở hạn 60 giờ, còn sai số quỹ đạo trong thử nghiệm MIX giảm lần lượt $12 \%$ và $14,2 \%$ so với GFS ở hạn 60 giờ và 72 giờ, ngoài ra thử nghiệm MIX có sai số qũy đạo giảm $12 \%$ so với thử nghiệm MPH ở hạn 60 giờ.

Về cường độ bão, kết quả của 4 trường hợp mô phỏng cho thấy, dự báo Pmin trong các thử nghiệm MPH, CIMSS, RADS và MIX hiệu quả hơn so với số liệu GFS. Ngoài ra, ở hạn dự báo dài hơn 48 giờ sai số Pmin trong các thử nghiệm CIMSS, RADS và MIX lại nhỏ hơn sai số Pmin trong thử nghiệm MPH, đặc biệt sai số Pmin trong thử nghiệm CIMSS lại nhỏ hơn sai số Pmin trong thử nghiệm RADS và MIX (hình 16). Như vậy, số liệu quan trắc được bổ sung trong đầu vào của mô hình có tác động tích cực đến dự báo PMIN, song song với VMAX, từ hạn dự báo sau 48 giờ thử nghiệm CIMSS dự báo VMAX hiệu quả hơn thử nghiệm MPH và GFS (hình 19), và hạn dự báo 60 và 72 giờ các thử nghiệm CIMSS, RADS và MIX dự báo hiệu quả Vmax. Như vậy, số liệu gió quan trắc từ vệ tinh, số liệu cao không và số liệu hỗn hợp (vệ tinh và cao không) tác động tích cực đến kết quả dự báo quỹ đạo và cường độ cơn bão Haiyan. Đặc biệt số liệu gió quan trắc từ vệ tinh là nguồn số liệu đáng tin cậy vì kết quả mô phỏng hoàn lưu qui mô lớn, quỹ đạo và cường độ bão Haiyan được cải thiện đáng kể so với các thử nghiệm còn lại. Kết quả này phù hợp với các nghiên cứu trước đây trong bài toán dự báo quỹ đạo và cường độ bão $[5,11,12]$.

Đóng góp của tác giả: Xây dựng ý tưởng nghiên cứu: T. T. M. H., P. T. M.,; Lựa chọn phương pháp nghiên cứu: T. T. M. H., P. T. M., N. T. H..; Xử lý số liệu: T. T. M. H., P. T. M., N. T. H, T. V. S.; Phân tích kết quả: T. T. M. H., P. T. M., N. T. H.;; Viết bản thảo bài báo: T. T. M. H., P. T. M., N. T. H, N. V. T.,; Chỉnh sửa bài báo: T. T. M. H., P. T. M., N. T. H., N. V. T., T. V.S.

Lời cam đoan: Tập thể tác giả cam đoan bài báo này là công trình nghiên cứu của tập thể tác giả, chưa được công bố ở đâu, không được sao chép từ những nghiên cứu trước đây; không có sự tranh chấp lợi ích trong nhóm tác giả.

\section{Tài liệu tham khảo}

1. Hunt, BR.; Kostelich, EJ.; Szunyogh, I. Efficient data assimilation for spatiotemporal chaos: A local ensemble transform Kalman Filter. Physica D. 2007, 230, 112-126.

2. Hong, L.; Kalnay, E.; Miyoshi, T.; Danforth, C.M. Accounting for model errors in ensemble data assimilation. Mon. Weather Rev. 2009, 137, 3407-3419.

3. Miyoshi, T.; Yamane, S. The Gaussian Approach to Adaptive Covariance Inflation and Its Implementation with the Local Ensemble Transform Kalman Filter. Mon Weather Rev. 2007, 139, 1519-1535.

4. Miyoshi, T.; Kunii, M. The Local Ensenble Transform Kalman Filter with the Weather Rearch and Forecasting Model: Experiments with Real Observation. Pure Appl. Geophy. 2012, 169, 321-333. 
5. Kieu, C.Q.; Truong, N.M.; Mai, H.T.; Ngo-Duc, T. Sensitivity of the Track and Intensity Forecasts of Typhoon Megi (2010) to Satellite-Derived Atmosphere Motion Vectors with the Ensenble Kalman filter. J. Atmos. Oceanic Technol. 2012, 29, 1794-1810.

6. https://vi.wikipedia.org/wiki/B\%C3\%A3o_Haiyan_(2013)\#Vi\%E1\%BB\%87t_Nam

7. http://www2.mmm.ucar.edu/wrf/users/docs/user_guide_V3.9/contents.html

8. https://www.metoc.navy.mil/jtwc/jtwc.html?best-tracks

9. http://tropic.ssec.wisc.edu

10. Wilks Daniel, S. Statistical Methods in the Atmospheric Scienes. Ithaca New York 1997, 59, 255.

11. Tiến, T.T.; Mai, H.T.; Thanh, C. An Application of the Ensemble Kalman Filter on 5 days Forcasting Track and Intensity Tropical Cyclone. VNU J. Sci. Nat. Sci. Technol. 2013, 29, 201-206.

12. Tien, D.D.; Thanh, N.D.; Mai, H.T.; Chanh, K. A study of the connection between tropical cyclone track and intensity errors in the WRF model. Meteorol. Atmos. Phys. 2013, 121, 3-4, 12.

\title{
Assimilation of satellite wind and upper-air sounding data to simulate the track and intensity of the Haiyan typhoon 2013
}

\section{Tran Thi Mai Huong ${ }^{1, *}$, Nguyen Thi Hang ${ }^{2}$, Nguyen Van Tin ${ }^{3}$, Tran Van Son ${ }^{1}$, Pham Thi Minh ${ }^{1}$}

1 Department of Meteorology, Hydrology and Climate change, Ho Chi Minh University of Natural Resources and Environment; ttmhuong@hcmunre.edu.vn; tvson@hcmunre.edu.vn; minhpt201@gmail.com.

2 Department of General Science Ho Chi Minh University of Natural Resources and Environment; hang.nguyen687@gmail.com.

${ }^{3}$ Marine environment and resources management, Ho Chi Minh University of Natural Resources and Environment; nvtin@hcmunre.edu.vn.

\begin{abstract}
The study conducted experiments with the assimilation of satellite wind data (CIMSS), upper-air sounding data assimilation (RADS), mixed data (satellite wind+upper-air sounding data-MIX) by ensemble Kalman filter and multi-physics Ensemble forecast (MPH). Test results show that, for each type of monitoring data, the trend and intensity of the general circulation in the tests are different. In particular, the simulations of CIMSS, RADS and MIX data for trends and the intensity of the general atmospheric circulation are more similar to the actual development than the test without using monitoring data (MPH), whereby the trajectory Haiyan storm was simulated quite by the actual track with statistical errors in 6 test cases significantly reduced. Specifically, the tracking error in the CIMSS trial improved by $14 \%$ and $14.3 \%$ respectively in the 48 -hour forecast period and 72 hours compared with the MPH test and decreased 14\% and $23.9 \%$ respectively compared to the global GFS forecast, and the orbital error in the RADS test improved by $11.1 \%$ compared to the GFS and MPH at 60 hours forecast period, while the orbital error in the MIX test decreased by $12 \%$ and $14.2 \%$, respectively, compared to the GFS at the 60 hour forecast period and 72 hours, in addition to the MIX test, the orbital error was reduced by $12 \%$ compared to the MPH test at 60 hours. In terms of intensity, Pmin forecasts in MPH, CIMSS, RADS, and MIX tests are more efficient than GFS data. Where the Pmin error in the CIMSS test is smaller than the Pmin error in the remaining tests and the GFS data at the forecast term is longer than 48 hours. For Vmax, the CIMSS, RADS and MIX tests forecast Vmax effectively at the forecast period of 60 and 72 hours.
\end{abstract}

Keywords: The Kalman filter; WRF model; Typhoon; Ensemble forecasting. 